\title{
Contribution of Atmospheric Circulation to Inception of the Laurentide Ice Sheet at 116 kyr BP*
}

\author{
FrANCIS O. OTIENO \\ Polar Meteorology Group, Byrd Polar Research Center, The Ohio State University, Columbus, Ohio \\ DAVID H. BROMWICH \\ Polar Meteorology Group, Byrd Polar Research Center, and Atmospheric Sciences Program, Department of Geography, \\ The Ohio State University, Columbus, Ohio
}

(Manuscript received 29 August 2007, in final form 22 May 2008)

\begin{abstract}
The role of atmospheric circulations, yielding extremely cold summer and wet winter seasons, in the development of perennial snow cover over the inception region of the Laurentide Ice Sheet is investigated using the Community Land Model, version 3 (CLM3) with bias-corrected 40-yr ECMWF Re-Analysis (ERA-40) idealized atmospheric forcing. Potential contribution of changes in frequency of these extremes under contemporary and Eemian (116 kyr BP) conditions is also examined by adjusting the atmospheric forcing.

The results confirm that colder atmospheric temperatures during the melt season are more important than extreme amounts of winter snowfall. Increases in frequency of extremely cold and persistent summer air temperatures in the contemporary climate do not produce perennial snow. An additional cooling of $4^{\circ} \mathrm{C}$ together with adjustments for Eemian incident radiation is required for perennial snow to start growing around Hudson Bay. Deeper snow is found over the Labrador-Ungava area, close to the North Atlantic Ocean moisture sources, compared to the Keewatin area. These areas are in agreement with the locations of the Laurentide Ice Sheet domes found from free gravity analysis.

Starting from the warm present-day atmosphere a $25 \%$ decrease in summer insolation is required for CLM3 to develop perennial snow. This suggests that cooling resulting from modest decreases in local insolation in response to Milankovitch radiation forcing was insufficient for inception at $116 \mathrm{kyr}$ BP. Remote cooling or local feedbacks that amplify the impact of the modest insolation reductions are required. A large-scale atmospheric cooling appears to have played a decisive role in inception.
\end{abstract}

\section{Introduction}

It is generally assumed that variations in insolation resulting from changes in the characteristics of the earth's orbit are responsible for variations in the earth's climate on time scales of several tens of thousands of years. The Milankovitch theory postulates that changes in the earth's orbital parameters, which reduce summer insolation over high northern latitudes (Milankovitch 1941), allow winter snow to survive through summer

* Byrd Polar Research Center Contribution Number 1367.

Corresponding author address: Francis Ochieng Otieno, Polar Meteorology Group, Byrd Polar Research Center, The Ohio State University, 1090 Carmack Road, Columbus, OH 43210.

E-mail: otieno.1@osu.edu and thus initiate formation of ice sheets. Thus changes in ice volume should track changes in insolation. The precession, obliquity, and eccentricity are used to characterize the earth's orbit and hence insolation. Peaks in ice volume records based on $\delta^{18} \mathrm{O}$ show cycles of $\sim 41$ kyr period between 2.75 and 0.9 million years ago and are presently dominated by cycles ranging between $\sim 80$ and $\sim 120$ kyr (Broecker et al. 1968; Broecker and van Donk 1970; Kukla and Kocí 1972; Hays et al. 1976; Muller and MacDonald 1997; Ruddiman 2006). Furthermore, spectral analysis of insolation in the $\sim 80$ to $\sim 120 \mathrm{kyr}$ periods shows negligible power and has led to the characterization of Milankovitch forcing as a "pace maker" whose impact requires feedbacks to amplify its effects. Among the feedbacks that have been examined are changes in greenhouse gases $(\mathrm{GHG})$ and in particular changes in $\mathrm{CO}_{2}$ concentration. The roles of 
meridional overturning circulation in the North Atlantic Ocean, vegetation, and sea surface temperatures (SST) have also been considered.

The last interglacial lasted from about 130000 to 115000 years before present and the period is known as the Eemian epoch. In this study we focus on the end of this period and investigate the potential contribution of increased frequency of extremely heavy winter snowfall and colder summer temperatures to glacial inception under present-day and 116000 years before present (116 kyr BP) insolation.

Orbital characteristics that decrease the sun-earth distance are thought to have the greatest impact on surface insolation. However Hall et al. (2005) suggest that, even in wintertime when the earth is closest to the sun, changes in surface temperature are not directly traceable to radiative forcing but to excitation of the northern annular mode. Also, SST changes in the tropical Pacific Ocean may be sufficient to switch North America from a nonglaciated state to a state with intermittent glaciations (Huybers and Molnar 2007). Many early inception studies focusing on the role of decreases in insolation using general circulation models (GCMs) failed to yield perennial snow cover (Rind et al. 1989). Vettoretti and Peltier (2004) have found that tuning a mixed layer ocean model to reproduce modern SST enables inception in the Canadian Climate Center Atmospheric GCM2. Other experiments using specified SSTs have also been able to simulate perennial snow cover with orbital changes (Dong and Valdes 1995; De Noblet et al. 1996; Yoshimori et al. 2002). The aforementioned failures may therefore be attributed to warm bias in the global models. Inadequate coupling of the atmosphere, biosphere, and ocean resulting in decreased sensitivity has also been suggested (Ramstein et al. 2005).

Early failures of modeling efforts and the indirect connection between Milankovitch cycles and variations in ice volume stimulated interest in a number of feedbacks that could amplify the moderate insolation changes. It is generally accepted that the existence of a perennial snow cover is a necessary condition for ice sheets to grow. Khodri et al. (2001) found perennial snow cover in simulations with the L'Institut PierreSimon Laplace Coupled Model, version 2 (IPSL CM2) and concluded that strong amplification of initial cooling occurred due to ocean feedbacks in the high northern latitudes. Meisner et al. (2003) found a southward shift in the tree line and a decrease in the meridional overturning circulation when land surface processes were included in their model and suggested that sea ice amplifies the cooling from decreased $\mathrm{CO}_{2}$ and insolation. More recently, Kubatzki et al. (2006) used the
Climate and Biosphere Groupe (CLIMBER-2) earth system model and found that ocean and vegetation changes have a crucial impact on glacial inception, but the impact of $\mathrm{CO}_{2}$ reductions on ice sheet development at the end of the Eemian was small. Their results suggest that having an interactive ocean was more important than having interactive vegetation in transient simulations beginning at the peak of the Eemian. Vettoretti and Peltier (2004), on the other hand, found that $\mathrm{CO}_{2}$ forcing may be of the same order as precessioneccentricity variations or ocean impacts. Ruddiman (2006) suggests that $75 \%$ of the amplitude of ice buildup with $\sim 100 \mathrm{kyr}$ periodicity is caused by internal feedbacks involving $\mathrm{CO}_{2}$ and ice albedo. Only $25 \%$ of the increase in ice volume was inferred to be due to changes in insolation.

Carbon dioxide feedbacks can accelerate ice sheet ablation when orbital-induced warming of the deep oceans allow for ventilation of $\mathrm{CO}_{2}$ from the ocean, which then amplifies the warming (Stott et al. 2007). Conversely, $\mathrm{CO}_{2}$ sequestration in colder equatorial oceans could induce positive feedbacks, which favor inception (Vettoretti and Peltier 2004). It is still an open question how such a drawdown in atmospheric $\mathrm{CO}_{2}$ could occur at the $\sim 80$ to $\sim 120 \mathrm{kyr}$ cycles seen in ice volume in direct response to modest changes in insolation. According to Soon (2007), variations in atmospheric $\mathrm{CO}_{2}$ generally follow changes in temperature, and published literature fails to quantitatively confirm $\mathrm{CO}_{2}$ as the prime mover of glacial cycles.

It is evident from these studies that the roles of insolation, GHG, vegetation, sea ice, and ocean temperatures in the inception process have received a lot of attention while changes in atmospheric circulation and, in particular, increases in frequency of extreme events have not. In the experiments described later we will determine whether or not perennial snow, a precursor for ice sheet inception, can form in response to increased frequencies of extremely cold spring and summer temperatures together with extreme winter snowfall. We also examine the impact of a combination of these extremes together under present-day as well as 116 kyr BP insolation.

Unless some drastic climate change eliminates global warming in the contemporary climate, the next glacial will almost certainly start from a climate state that is at least as warm as at present. This study therefore uses the present climate to initialize the simulations. The present-day atmospheric forcing certainly includes warming associated with increasing GHG concentrations. However, paleorecords show that temperatures at the peak of the Eemian were warmer than present (Kühl and Litt 2003; Bianca et al. 2006; Gebhardt et al. 
2007). We acknowledge that the cause of the warm atmosphere during the Eemian is not the same as the GHG-induced warming of the contemporary climate. But, in either case inception must proceed from a warm climate state and our understanding of exactly how this happens remains limited.

The significance of meteorological aspects and related feedbacks on glacial inception has been recognized since the 1950s (Willet and Sanders 1959). Alt (1987) found that intrusion of a ridge into the Queen Elizabeth Islands is associated with high melt while a deep cold trough across Ellesmere Island suppresses melting. Successively colder climates enhance poleward flux of moisture to the inception regions through increased baroclinic eddy activity due to intensified meridional temperature gradients (Barry 1966; Vettoretti and Peltier 2003). Moisture advection may in turn result in increased cloud cover, potentially amplifying orbital-induced reductions in insolation.

Interannual variations in the date of snowmelt onset depend on, among other things, the characteristics of the overlying air mass through its influence on downward longwave radiation. Snow cover disappears early during warm wet springs and later in cold and dry springs (Zhang et al. 1996, 1997, 2001). Bromwich et al. (2002) examined atmospheric circulations that favor glacial inception in the contemporary climate as depicted in the National Centers for Environmental Prediction (NCEP) and the National Center for Atmospheric Research (NCAR) reanalysis (NNR). They found rare occurrences of the cold summer/wet winter criteria for glaciation, consistent with lack of glaciation in contemporary climate and suggested that a change in frequency of these occurrences could favor inception. A high positive correlation between the North Atlantic Oscillation (NAO) and annual snow mass balance in the middle latitudes has also been reported by Reichert et al. (2001). More recently, Gardner and Sharp (2007), using NNR, have also shown a strong connection between the position and strength of the 500-hPa circulation, the mean July air temperature, and the annual glacier mass balance for the Canadian high Arctic. Vortices centered in the Western Hemisphere had positive snow mass balance compared to those in the Eastern Hemisphere. We note here that the coldest summer identified [June-August (JJA) 1972] by Bromwich et al. (2002), and which is used in this study, has a vortex centered near Baffin Bay (Fig. 1) and is thus consistent with the Gardner and Sharp (2007) configuration for positive mass balance. In this season the northerly flow decreased air temperature throughout the lower and middle troposphere. Thus an increase in the frequency of such vortex configurations would potentially result in glacial inception. To investigate this likelihood we use an idealized atmosphere to drive the Community Land Model, version 3 (CLM3) (Oleson et al. 2004) in offline integrations. The experimental setup described later allows us to specify a representative atmospheric forcing that mimics the Eemian atmosphere at the land-atmosphere interface where interactions between the land and atmosphere occur.

In section 2 we describe the data and method used to specify the idealized atmospheric forcing and the necessary adjustments for bias in atmospheric forcing data. This is followed in section 3 by a description of CLM3 and the experiments performed with it. There are a total of seven experiments; four sensitivity experiments address the impact of changing frequency of seasonal extremes associated with the atmospheric circulation in the contemporary climate and three additional experiments focus on these extreme circulations with $116 \mathrm{kyr}$ BP insolation. The results are presented in section 4 followed by the summary and discussions in section 5 and then the conclusions in section 6 .

\section{Data}

CLM3 requires atmospheric wind speed, temperature, specific humidity, or water-vapor mixing ratio at a specified level above the surface; the default is $30 \mathrm{~m}$, which is used here. CLM3 derives its own ground and surface $(2 \mathrm{~m})$ air temperatures. Downwelling shortwave radiation and precipitation rate are also needed over the region and period of integration. In the Arctic these data are not available, hence the two reanalyses-NNR and the 40-yr ECMWF Re-Analysis (ERA-40)-are commonly used. The ERA-40 covers the period 19572002 at 6-h intervals. Additional information on ERA40 is available from Gibson et al. (1997) and Uppala et al. (2005), among others. In general, any reanalysis product will be strongly influenced by the dynamics of the underlying model in areas of sparse data (Kalnay et al. 1996) such as the Arctic. It is therefore important to remove any model biases from the atmospheric forcing prior to using the data because CLM3 is very sensitive to the atmospheric forcing.

Both ERA-40 and NNR have been evaluated extensively and their potential and shortcomings in the high northern latitudes are well documented (Serreze and Maslanik 1997; Serreze et al. 1998; Serreze and Hurst 2000; Cullather et al. 2000; Rogers et al. 2001; Serreze et al. 2003, 2005; Bromwich and Wang 2005, Bromwich et al. 2007). According to Serreze et al. (1998), NNR shortwave radiation fluxes are too large for all months and are caused by large underestimates in cloud fraction or optical thickness. Serreze and Hurst (2000) find that predictions from the original (15 yr) ECMWF Re- 

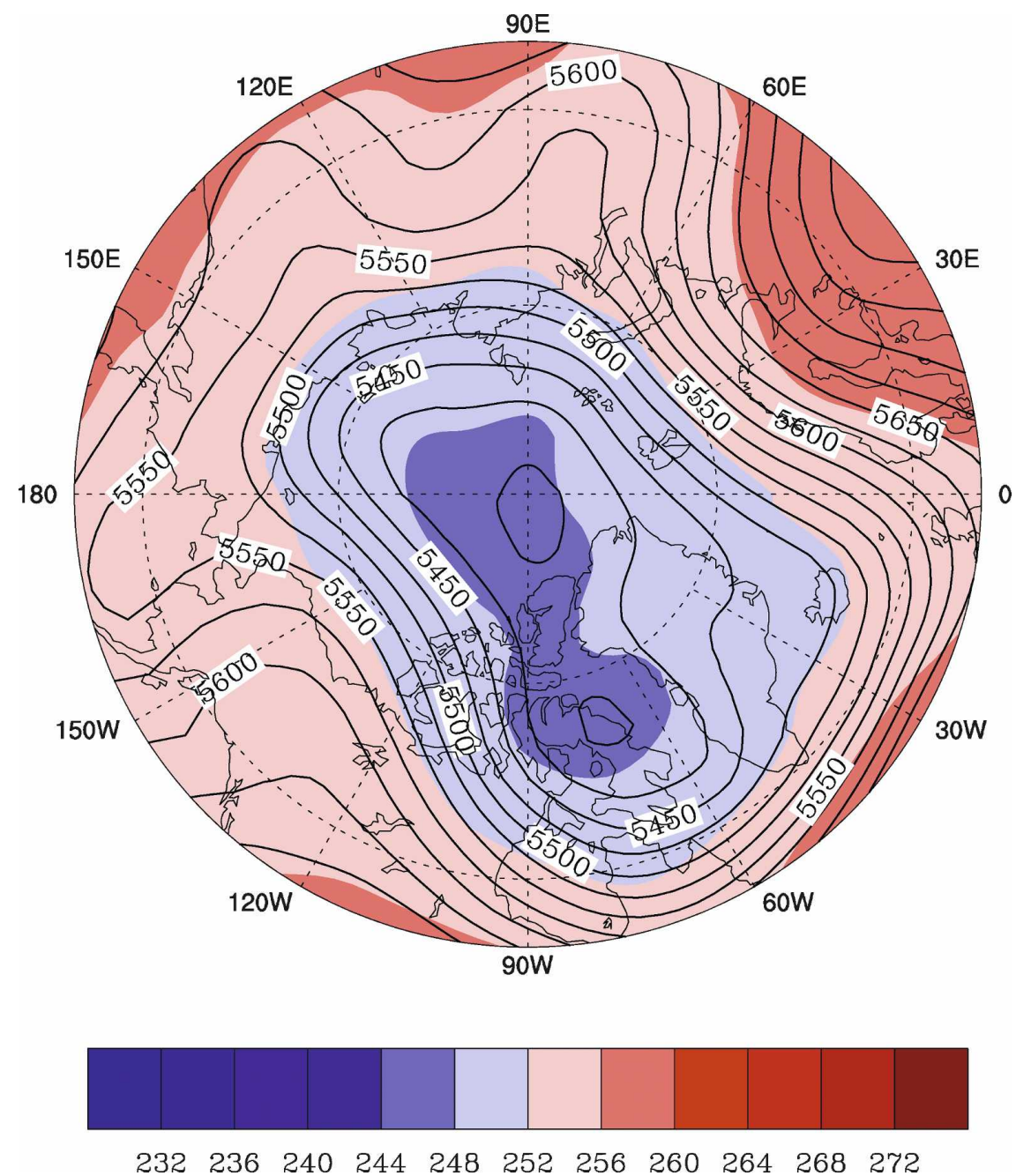

FIG. 1. Height of 500-mb geopotential (m) and air temperature (K) in JJA 1972 that is used for the summer of the idealized year.

Analysis (ERA-15) (Gibson et al. 1997) are better than NNR overall. ERA-40 shows low $( \pm 25 \%)$ mean precipitation bias and higher squared correlations relative to the observations, indicating an improved depiction of interannual variability (Serreze et al. 2005). Bromwich et al. (2007) found that ERA-40 captures the cloud variability better than NNR but the clouds are still too optically thin and allow excess downwelling shortwave fluxes to the surface. In light of the superior performance of ERA-40 over the Arctic and scarcity of observations we chose to drive CLM3 with the reduced Gaussian grid (N80) ERA-40 reanalysis.

\section{a. Bias correction}

The discussion above suggests that adjustments are still necessary to improve the ERA-40 representation of shortwave fluxes over our region of focus, shown in Fig. $2,\left(55^{\circ}-85^{\circ} \mathrm{N}, 120^{\circ}-60^{\circ} \mathrm{W}\right)$ and discussed later. We attempt to minimize uncertainty by using as much of the available data as possible. Monthly statistics are used in adjustment schemes that are similar to others previously applied to NNR (Berg and Famiglietti 2003; Sheffield et al. 2004; Qian et al. 2006). We use ERA-40 winds unchanged because they exhibit small bias and reasonably capture the tropospheric wind variability with respect to field observations from the Lead Experiment in the Beaufort Sea (LeadEx) (Bromwich and Wang 2005). Our aim in these adjustments is to minimize the impact of biases in the idealized atmospheric forcing: hence no correction is made for possible trends in the ERA-40 as would be required to produce consistent long-term atmospheric forcing.

\section{1) Air temperature AND HUMidity}

The Arctic land surface temperature data (Willmott and Rawlins 1999) is used in a ratio-based correction to 


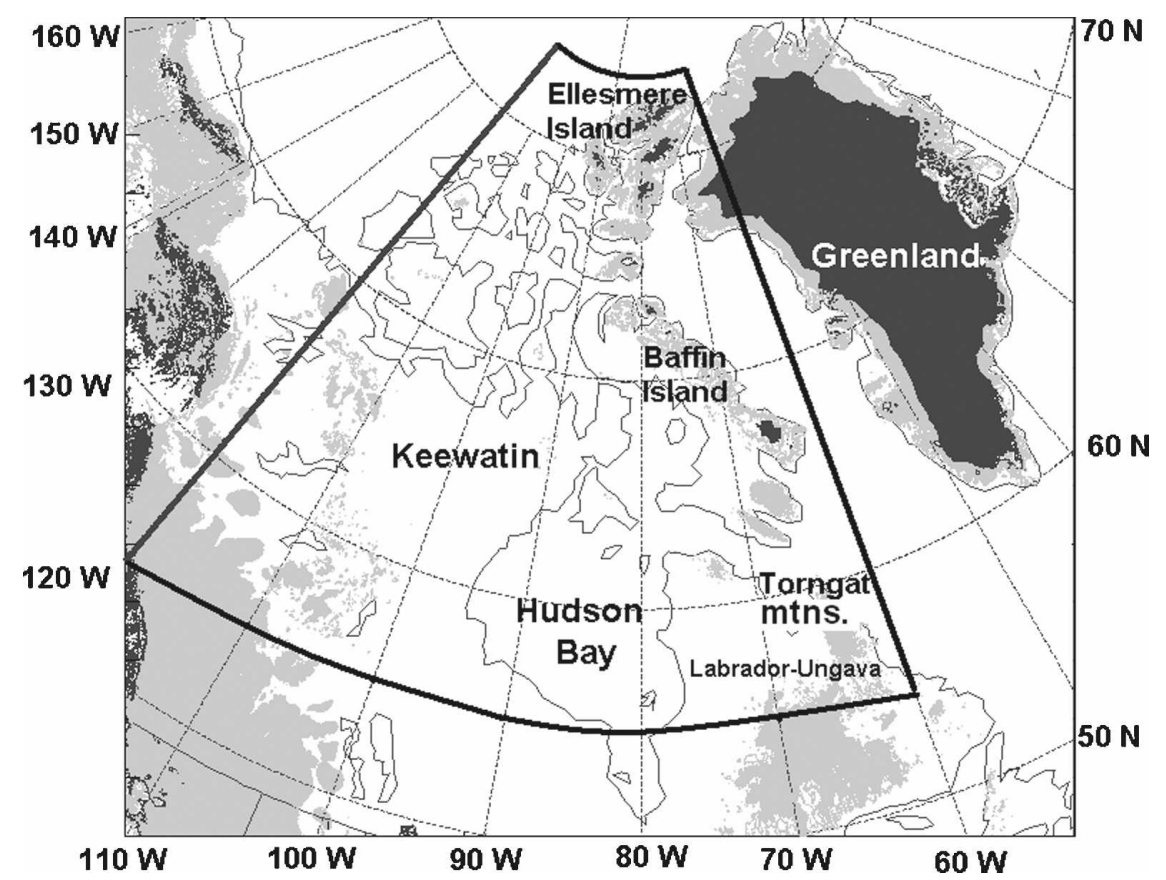

FIG. 2. Region of study with elevations above $500 \mathrm{~m}$ (light-gray shading) and $1000 \mathrm{~m}$ (dark-gray shading); thick line encloses area of focus for the analysis $\left(55^{\circ}-85^{\circ} \mathrm{N}, 120^{\circ}-60^{\circ} \mathrm{W}\right)$.

make adjustments for mean bias to the ERA-40 2-m air temperature. Adjustments are also made to take into account of the effects of differences between the ERA40 and observed surface elevation. We use surface elevation data from the National Geophysical Data Center $(\mathrm{NGDC})($ Sloss 2001$)$ at $2^{\prime} \times 2^{\prime}$ resolution $(\sim 3.7$ $\mathrm{km})$ for this correction. The N80 gridded ERA-40 atmospheric forcing is interpolated to $1^{\circ} \times 1^{\circ}$ regular latitude-longitude grid. Adjustments to temperature then involve corrections for both the height differences and long-term bias using Eq. (1) at each grid point:

$$
T_{i, \text { adj }}=\frac{T_{\mathrm{obs}, m}}{\left(T_{e 40, m}+\Delta z \Gamma_{e}\right)}\left(T_{e 40, i}+\Delta z \Gamma_{e}\right),
$$

where $\Delta z$ is the difference between ERA-40 and observed elevations at each grid point; $T_{\mathrm{obs}, m}$ and $T_{e 40, m}$ are the long-term mean (LTM) monthly air temperatures (1958-2001) from the $0.5^{\circ} \times 0.5^{\circ}$ gridded monthly climatology of Arctic land surface from the University of Delaware (UDW) (Willmott and Rawlins 1999) and ERA-40, respectively. Here $T_{e 40, i}$ is the 6-hourly ERA$402-\mathrm{m}$ air temperature before adjustment, and $T_{i \text {,adj }}$ is the 6-hourly adjusted air temperature used in CLM3. The period 1958-2001 is used because it encompasses all years with data for all of the months from both datasets.

The UDW air temperatures were corrected for el- evation using the average environmental lapse rate $\Gamma_{e}$ $\left(0.006^{\circ} \mathrm{C} \mathrm{m}^{-1}\right)$; hence we use the same lapse rate to adjust ERA-40 temperatures. The significance of these adjustments is discussed in section $4 a$. Because gridded fields of dewpoint temperature for the Arctic are not available, the same adjustments as temperature are therefore applied to ERA-40 dewpoint temperatures. This is done to avoid creating spurious changes in relative humidity that is computed from the adjusted surface air temperatures.

\section{2) Downwelling SHORTwave RAdiation}

A comprehensive climatology of Arctic radiation has been compiled (Serreze et al. 1998; Box et al. 1998) for regions north of $65^{\circ} \mathrm{N}$. We use the ratio of monthly averages of downwelling shortwave radiation from these data to the ERA-40 monthly shortwave radiation climatology to correct the excessive downwelling shortwave flux at the surface in ERA-40 (Bromwich et al. 2007). Most of the land stations around Baffin Island only have complete radiation data between 1971 and 1990. Therefore, the observed monthly mean statistics for the period 1971-90 are used in the radiation corrections instead of the 1958-2001 period, which was used for the temperature adjustments.

We chose to compare ERA-40 downwelling shortwave radiation at $116 \mathrm{kyr} \mathrm{BP}$ and at present using the 


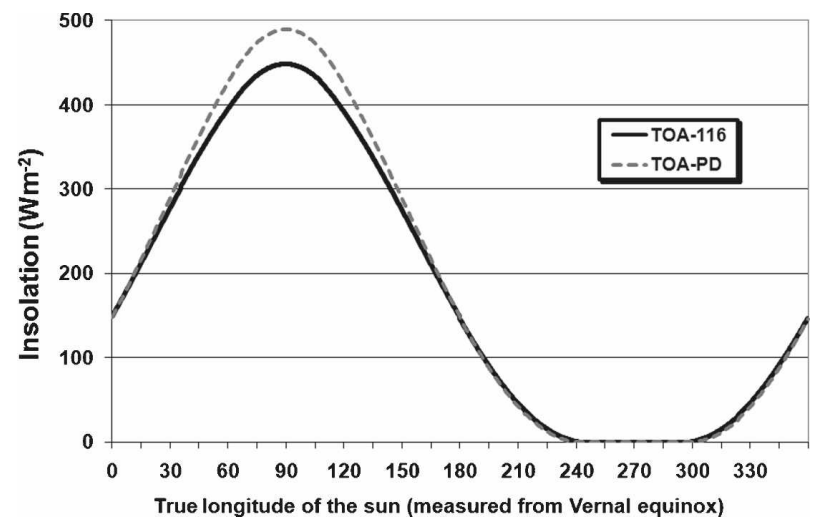

FIG. 3. Insolation $\left(\mathrm{W} \mathrm{m}^{-2}\right)$ at the TOA at $70^{\circ} \mathrm{N}$ as a function of the position of the earth in its orbit at $116 \mathrm{kyr}$ BP (TOA-116, continuous) and present day (TOA-PD, dashed line). True longitude equal to zero is the point of vernal equinox (Berger 1978).

same positions in the earth's orbit [true longitude of the sun, Laskar et al. (1993)] because the number of days in the seasons differ between the two epochs owing to the precession and elliptical shape of the earth's orbit (Kutzbach and Otto-Bliesner 1982; Joussaume and Braconnot 1997; Crucifix et al. 2006). Figure 3 shows that at the same position (true longitude) as the present-day summer solstice, the present-day top of the atmosphere (TOA) insolation exceeds that at $116 \mathrm{kyr}$ $\mathrm{BP}$ at $70^{\circ} \mathrm{N}$ (Berger 1978). We use the ratio of the daily mean insolation change based on this angular definition of seasons to adjust the ERA-40 insolation for both insolation changes and mean bias. Applying top of the atmosphere changes at the surface implicitly assumes no change in atmospheric transparency. Changes in clouds and dust in the atmosphere, which are not accurately known at $116 \mathrm{kyr} \mathrm{BP}$, ultimately determine how much change occurs at the surface. Therefore our applied changes are likely larger than would occur in the real world.

\section{3) Precipitation}

A common problem with many global gridded precipitation datasets (Chen et al. 2002; Adler et al. 2003; Matsuura and Willmott 2005) is the lack of correction for gauge undercatch of solid precipitation due to wind effects (Yang et al. 2005) and underrepresentation of high elevation precipitation at high latitudes (Adam et al. 2006). This reduces the accuracy and results in substantial differences among existing gridded precipitation for these regions. One approach that has been used to correct for the biases (Tian et al. 2007; Yang et al. 2005) requires development of catch ratios (CR), which depend on concurrent observations of temperature and wind speed (Goodison et al. 1998). The number of sta- tions that could be used to obtain $\mathrm{CR}$ values in the inception region is small and most stations are located in low-lying coastal regions. Since the CR values are for individual stations, interpolating their values to regions of high elevations with no stations would introduce uncertainty in the corrected precipitation. Sheffield et al. (2004) also point out that correction methodology could compromise spatial consistency on daily time scales. Yet CLM3 requires subdaily precipitation rates. Furthermore, Tian et al. (2007) quantified the impact of undercatch errors on CLM3 simulated snow depths north of $45^{\circ} \mathrm{N}$. Their results show that differences in winter snow depth due to undercatch errors in the inception region are small $(0.06 \mathrm{~m})$. The relatively small ERA-40 mean bias, the potential uncertainty in computed CR factors, and the small impact on CLM3 simulated snow depths due to precipitation correction suggest that adjustments to ERA-40 precipitation may be of limited value here. Because the amount of snow in CLM3 also depends on the atmospheric temperature that has already been adjusted, no additional adjustments are made to the ERA-40 precipitation.

\section{b. Idealized atmospheric forcing and region of study}

Can CLM3 simulate the perennial snow required for inception when forced by an idealized atmosphere that has increased frequency of occurrence of extremely wet winters followed by extremely cold spring and summer seasons? To identify such an idealized atmosphere, we identified extreme seasons in the contemporary climate from the ERA-40 reanalysis. The extreme seasons are defined as those with normalized deviations whose absolute magnitude exceed one standard deviation $(1 \sigma)$, while the normal seasons have deviations that are less than $0.5 \sigma$. The approach used to identify the extreme seasons is similar to Bromwich et al. (2002) who used NNR and we focus on the Canadian archipelago and Baffin Island (Fig. 2) region. Figure 4 shows that both NNR and ERA-40 generally show similar temperature and precipitation variability and identify nearly the same extreme seasons over the study region, although the magnitudes differ somewhat. Our idealized year uses seasons from different years because occurrence of favorable circulations in all seasons of any one year is rare. ERA-40 reanalysis shows that 1972 had nearnormal precipitation in spring and summer but was extremely cold. Other years with appropriate fall and winter characteristics are summarized in Table 1 . The analysis in this study focuses on the region bounded by $55^{\circ}-85^{\circ} \mathrm{N}, 120^{\circ}-60^{\circ} \mathrm{W}$. This area (Fig. 2) is slightly larger than that used in Bromwich et al. (2002) in order 
(a)

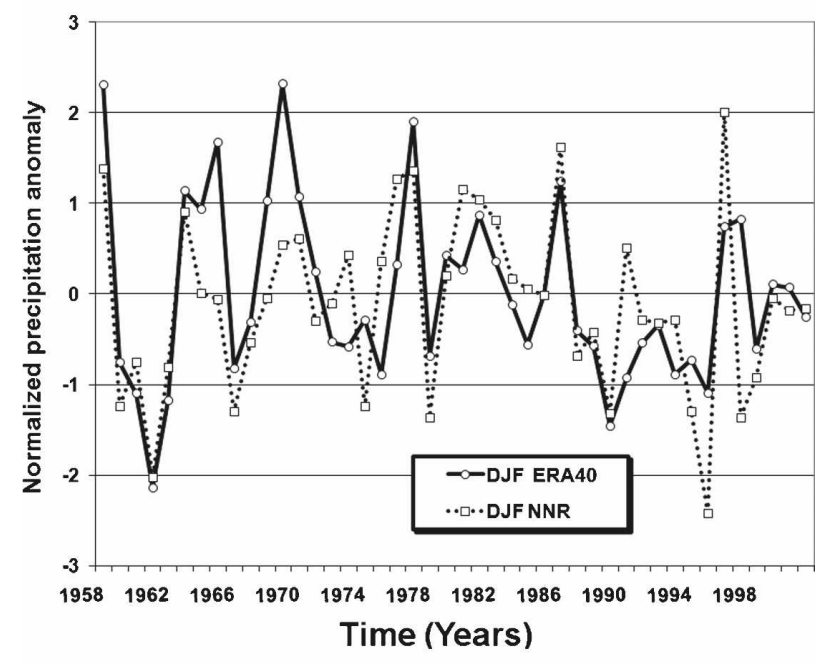

(b)

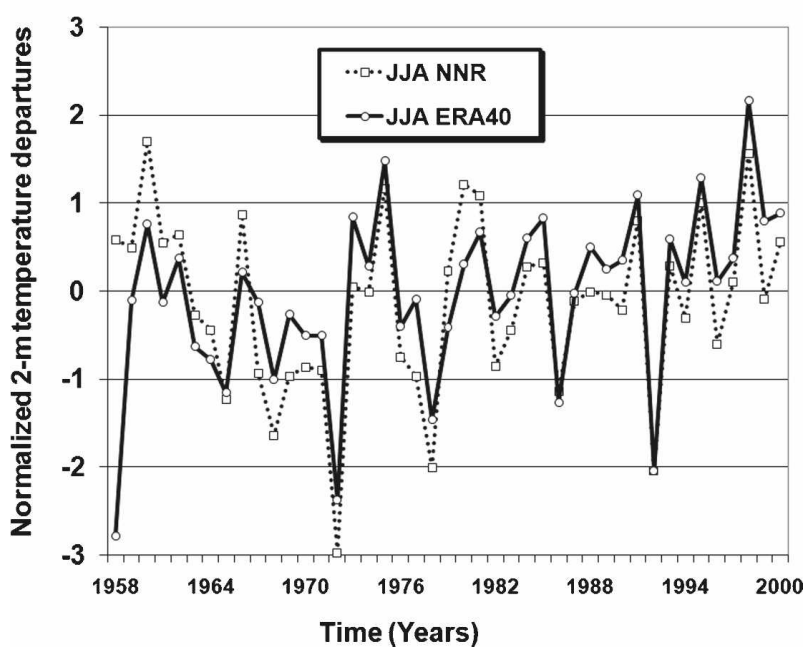

FIG. 4. (a) Normalized winter precipitation deviation from ERA-40 (DJF ERA-40: solid-circle) and NCEP-NCAR reanalysis (DJF NNR: dash-box) averaged over $50^{\circ}-80^{\circ} \mathrm{N}, 60^{\circ}-90^{\circ} \mathrm{W}$; the year in the time axis is the year in which January occurs during the respective DJF season. (b) Normalized summer (JJA) 2-m temperature deviations from ERA-40 (JJA ERA-40: solid-circle) and NCEP-NCAR reanalysis (JJA NNR: dash-box) averaged over $50^{\circ}-80^{\circ} \mathrm{N}, 60^{\circ}-90^{\circ} \mathrm{W}$.

to include the Canadian archipelago, extensive plateaus of Baffin Island, Labrador-Ungava, and Keewatin areas around Hudson Bay, which are believed to have played an important role in the inception (Ives 1957; Jacobs et al. 1974; Williams 1979; Dong and Valdes 1995). Williams (1979) showed that Baffin Island is likely to be the first area to respond to global cooling by forming an ice cover, as earlier proposed by Andrews and Barry (1978), based on snow line altitudes. Furthermore, Jacobs et al. (1974) found that circulations
TABLE 1. Precipitation and air temperature anomalies for seasons used to define the idealized year: September-November (SON), December-February (DJF), March-May (MAM), and June-August (JJA).

\begin{tabular}{llcll}
\hline \hline & SON & DJF & MAM & \multicolumn{1}{c}{ JJA } \\
& 1995 & $1968 / 69$ & \multicolumn{1}{c}{1972} & 1972 \\
\hline Precipitation & Wet & Wet & Near normal & Near normal \\
Temperature & Warm & Warm & Cold & Cold \\
\hline
\end{tabular}

associated with the extremely cold summer in 1972 were related to heavy snowfalls in the Baffin area.

\section{Model and experiments}

\section{a. Community Land Model CLM3}

CLM3 combines the best features of the Bonan Land Surface Model (Bonan 1996), the Biosphere-Atmosphere Transfer Scheme (BATS) (Dickinson et al. 1993), and the Institute of Atmospheric Physics land surface model (IAP94) (Dai and Zeng 1997). The current version of the Community Climate System Model, version 3 (CCSM3) (Collins et al. 2006) depends on CLM3 to perform calculations of surface fluxes of radiation, momentum, and latent and sensible heat in coupled configurations. The coupling allows for communications of the CLM3 computed fluxes to the atmosphere, which may change the atmospheric circulation. In this study, however, we want specific atmospheric conditions to persist. Since the model is well documented in a number of publications (Oleson et al. 2004; Levis et al. 2004; Vertenstein et al. 2004; Bonan et al. 2002; Zeng et al. 2002; Bonan and Levis 2006; Dickinson et al. 2006), only those aspects relevant to this study are discussed further.

Spatial heterogeneity in CLM3 is represented in a nested subgrid hierarchy. Simulated biogeophysical processes include canopy, snow, and soil hydrology along with soil heat transfers, fluxes of momentum, sensible heat, and latent heat. Snow parameterization in CLM3 comprises up to five layers, based on Anderson (1976), Jordan (1991), and Dai and Zeng (1997). The mass of water and ice in the snow layers together with layer thickness and temperature define the state of snow while neglecting the water vapor phase. Changes in the mass of ice are caused by accumulation from precipitation or frost or loss from sublimation in the top layer and phase changes in both the top and underlying snow layers. Snow water flows between layers when the holding capacity of the layer is exceeded. Snow compaction follows soil hydrology calculations, including infiltration, soil water movement, and subsurface drainage. Snow is not allowed to accumulate in wetlands if 
the surface temperature is above freezing. The standard CLM3 has snow water capped at $1000 \mathrm{~kg} \mathrm{~m}^{-2}$ for all surfaces; we eliminated the cap so as to allow an indefinite growth of the snow depth.

To use CLM3 for simulations of the Eemian land surface, the atmospheric forcing must also be representative of the Eemian climate because CLM3 is very sensitive to atmospheric forcing. Since CLM3 receives input from the bottom of the atmosphere, it is assumed that all atmospheric processes at $116 \mathrm{kyr} \mathrm{BP}$ have already been accounted for in the forcing data. We do this by adjusting values from ERA-40 for Eemian atmospheric temperature and insolation. In CLM3 the orbital configuration and $\mathrm{CO}_{2}$ concentration are set to those appropriate for $116 \mathrm{kyr}$ BP. CLM3 needs the orbital configuration because it computes its own net surface radiation. The output is used to diagnose processes that would favor inception of the Laurentide Ice Sheet.

\section{b. Experiments}

A total of seven experiments (Table 2) are used in this study to examine the impact of seasonal extremes on the development of perennial snow cover for present-day and also for $116 \mathrm{kyr}$ BP. In the present-day simulations, the air temperature in ERA-40 is adjusted for bias arising from differences in the elevation of ERA-40 surface from the observed surface elevations and also for observed monthly mean air temperature bias. For the end of the Eemian simulations, the summer insolation and air temperatures in ERA-40 are decreased to correspond to $116 \mathrm{kyr} \mathrm{BP}$. The orbital characteristics in CLM3 and $\mathrm{CO}_{2}$ concentrations are also set to those at $116 \mathrm{kyr} \mathrm{BP}$. This reduces $\mathrm{CO}_{2}$ concentrations to $250 \mathrm{ppmv}$ compared to the present $355 \mathrm{ppmv}$ in CLM3 (Table 2).

The first experiment, which serves as a control, has all seasons in the year near normal (NORML) and is used to assess the impact of changes in frequency of extreme seasons. The next three sensitivity experiments examine the roles of wet winter and cold summer seasons and a combination of both extremes in the contemporary climate. The first sensitivity experiment uses ERA-40 atmospheric forcing comprising a wet winter (WNWET) but is otherwise normal (precipitation and air temperature deviations from mean $<0.5 \sigma$ ) in the other seasons. The cold spring and summer experiment (SMCLD) has normalized spring and summer temperature deviations that are colder than the long-term mean (by at least $1 \sigma$ ) while the idealized (IDLZD) case has the extremely wet winters followed by cold spring and summer seasons. All four experiments use present-day $\mathrm{CO}_{2}$ and insolation.

The fifth experiment (INSOL) examines how sensi-

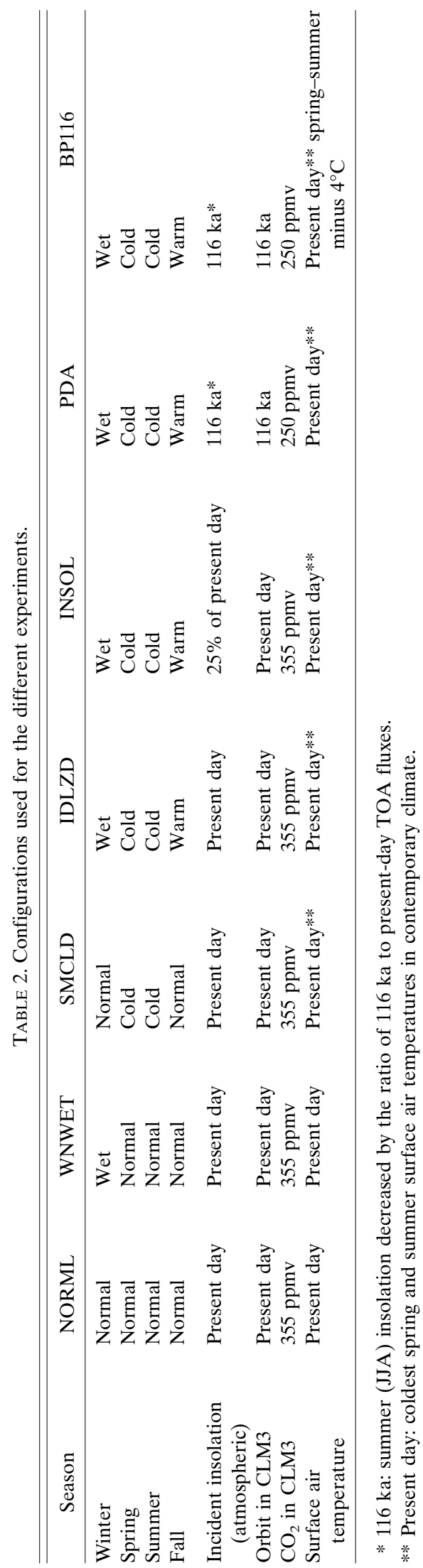


tive CLM3 is to reductions in incident insolation required to initiate perennial snow starting from presentday conditions. This experiments estimates reductions that would be required for inception if insolation and the associated local cooling was the only factor. The sixth experiment (PDA) uses $116 \mathrm{kyr}$ BP orbital setting and $\mathrm{CO}_{2}$ concentrations in CLM3 and present-day atmospheric temperature. The justification for using present-day temperatures is found in the literature, which suggests that the Eemian was at least as warm as the present climate. By maintaining present-day air temperatures and $116 \mathrm{kyr} \mathrm{BP}$ insolation we show that a warm atmosphere is capable of suppressing inception under the modest insolation decrease and reduced $\mathrm{CO}_{2}$ concentrations at $116 \mathrm{kyr} \mathrm{BP}$. The atmosphere can remain warm due to horizontal heat advection from outside the inception region.

A decrease in insolation in the absence of heat advection or other remote forcing would result in cooling of both the surface and atmosphere. Because our idealized configuration does not allow for a full response of the entire atmosphere to evolving surface conditions, the seventh experiment (BP116) is conducted under the assumption that, if the atmosphere were completely free to respond, it would cool down by amounts seen in paleorecords. Therefore, spring and summer atmospheric temperatures are cooled an additional $4^{\circ} \mathrm{C}$ from contemporary extremes. Previous studies have suggested that an initial cooling considerably greater than $6^{\circ} \mathrm{C}$ would have been required for inception (Loewe 1971; Landais et al. 2006). In the results that follow, the IDLZD experiment will be used to show the effect of increased frequency of extremes in the contemporary climate, while PDA and BP116 show the effect of the atmosphere under Eemian conditions.

\section{Results and discussion}

\section{a. Adjustments to ERA-40 air temperature and insolation}

Figure 5 shows that the ERA-40 2-m air temperatures averaged over $50^{\circ}-80^{\circ} \mathrm{N}, 60^{\circ}-90^{\circ} \mathrm{W}$ (as in Bromwich et al. 2002) do have a warm bias with respect to the observed surface air temperatures in the onset region throughout the year. During spring and summer the warm bias exceeds $5^{\circ} \mathrm{C}$, underscoring the importance of bias adjustment. The ERA-40 incident shortwave radiation has a positive bias (not shown) when compared to the radiation data from the Arctic Global Radiation (AGR) (Box et al. 1998; Serreze et al. 1998). This is consistent with that reported in Bromwich et al. (2007) for Barrow, Alaska, but is much smaller over Baffin

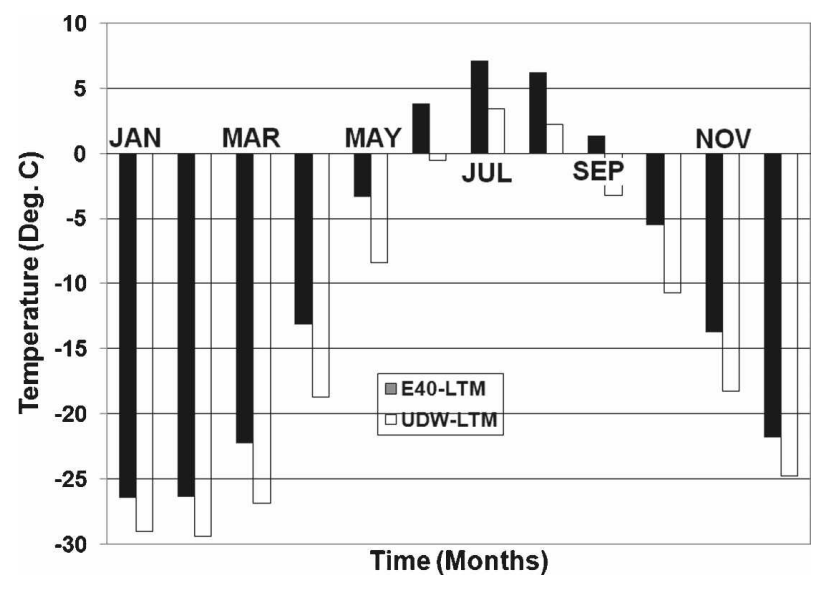

FIG. 5. Area-averaged $\left(50^{\circ}-80^{\circ} \mathrm{N}, 60^{\circ}-90^{\circ} \mathrm{W}\right)$ long-term mean (LTM) ERA-40 climatology (E40-LTM: gray hatched) and observed surface air temperature $\left({ }^{\circ} \mathrm{C}\right)$ from the University of Delaware (UDW-LTM: not hatched). UDW are adjusted for elevation; ERA-40 values are shown before adjustment and have a warm bias. The figure demonstrates the need for bias adjustment.

Island. Therefore the impact of the insolation adjustments is much smaller in the region of focus.

\section{b. Wet winter versus cold summer}

We use the fraction of ground that remains covered by snow at the end of the melt season in August as an indicator of whether or not the necessary perennial snow cover occurs in the simulations. Figure 6 shows the results for August in the IDLZD (Figs. 6a,c) and the BP116 experiments (Figs. 6b,d) after 5 years (top row) and 20 years (bottom row) of integration. The fraction of each grid covered in snow in eastern Baffin Island exceeds $60 \%$ at the end of the melt season in both experiments. The increase in the fraction covered after $20 \mathrm{yr}$ in the IDLZD experiment remains below $10 \%$ around Hudson Bay. In contrast, the BP116 with colder than present-day extreme summer air temperatures shows more than $70 \%$ coverage for grids around Hudson Bay that have snow by year 5. In going from 5 (Figs. 6a,b) to 20 (Figs. 6c,d) years of integration, the main difference is the increase in percentage of snow cover at the same grid points for both experiments. The aerial extent of perennial snow does not change much, suggesting that the ice sheet is growing by filling in the grids. However, comparing the left- and right-hand side panels it is evident that the area of snow-covered ground in Labrador-Ungava and Keewatin areas around Hudson Bay is substantially greater in the BP116 experiment compared to the IDLZD. The fraction of the grids covered around Keewatin in the IDLZD experiment reaches $10 \%$ in very small areas compared to the large areas with over $70 \%$ coverage in 

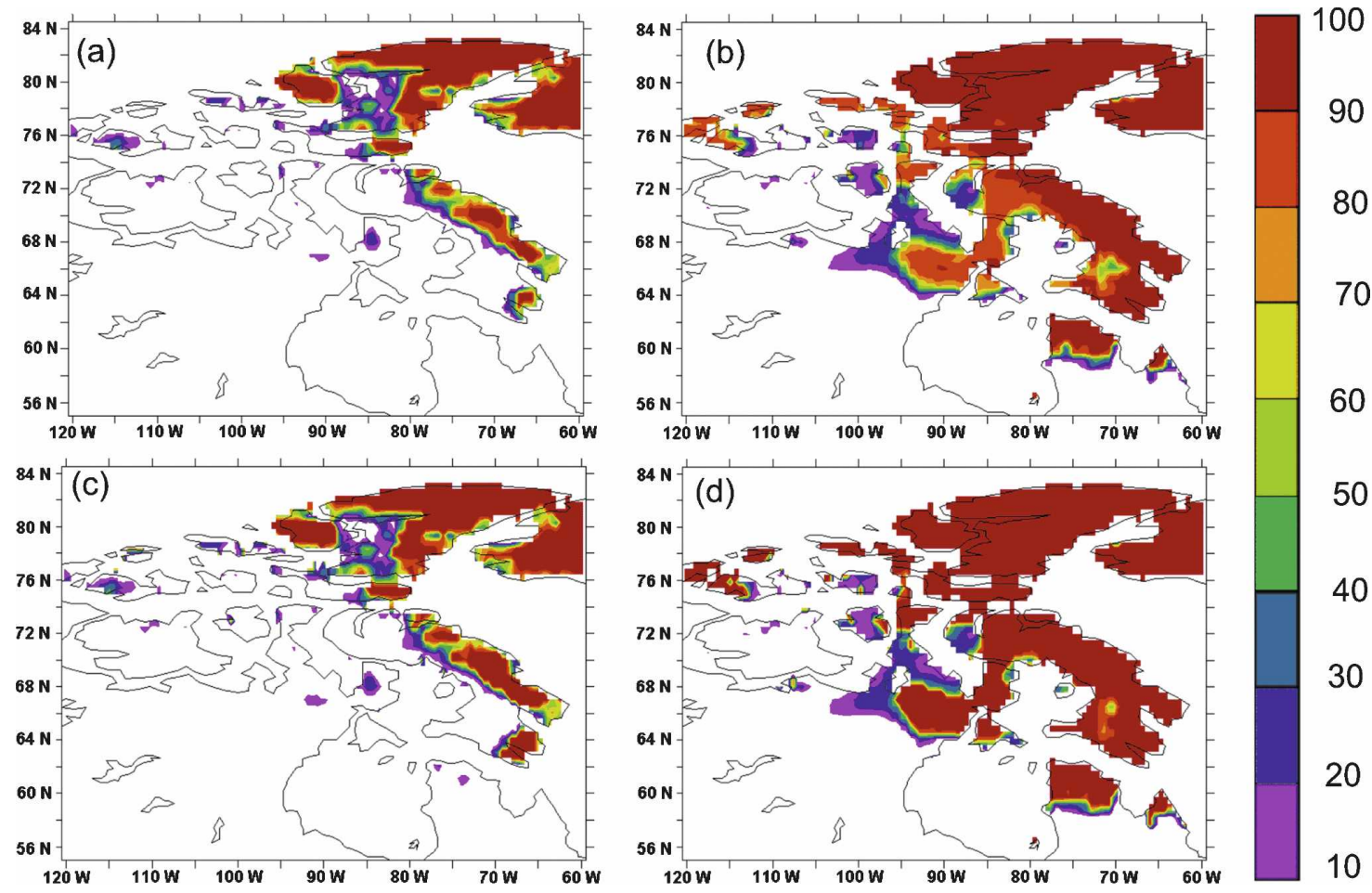

FIG. 6. Fraction (\%) of the ground covered by snow in August (a), (b) after 5 years of integration and (c), (d) after 20 years of integration for the (left) IDLZD experiment and (right) BP116 experiment.

BP116. Thus, the results show that an increase in frequency of the extreme events alone is not enough to lead to inception under present-day conditions. A colder atmosphere at the end of the Eemian would have provided more favorable conditions for southward expansion around Hudson Bay. Figure 7 reveals that grid points that have more than half of the area classified as glacier at the beginning of the simulations also

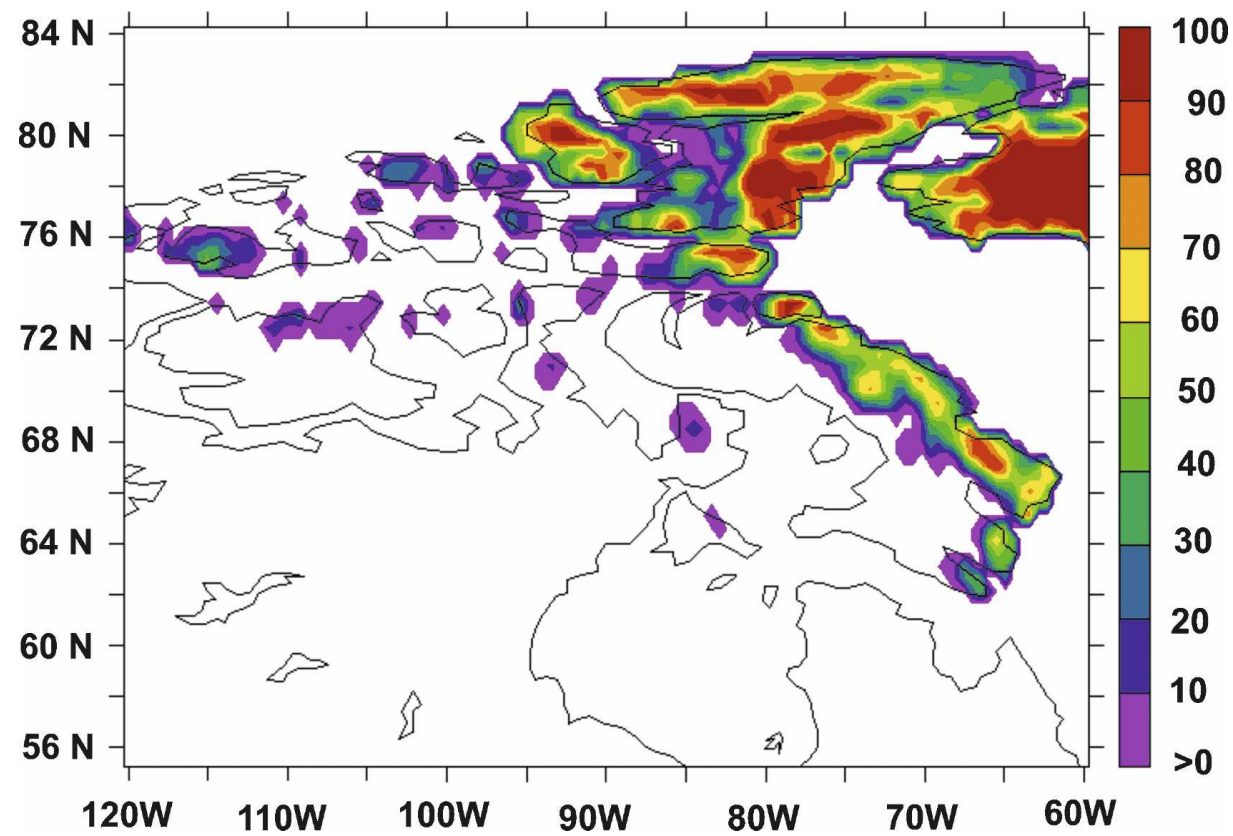

FIG. 7. Percentage of each grid box initially glaciated. 
(a)

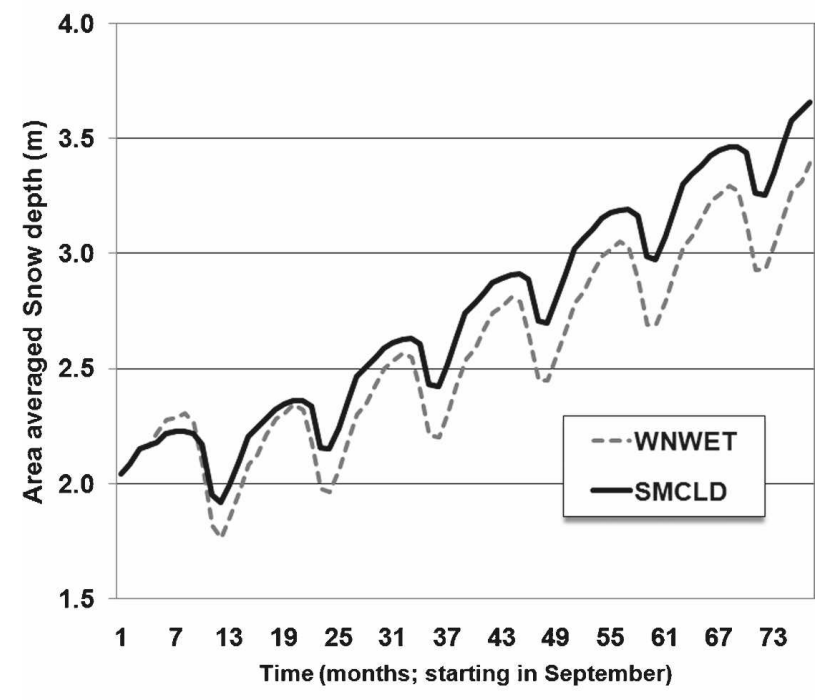

(b) August snow depth over non glaciated regions

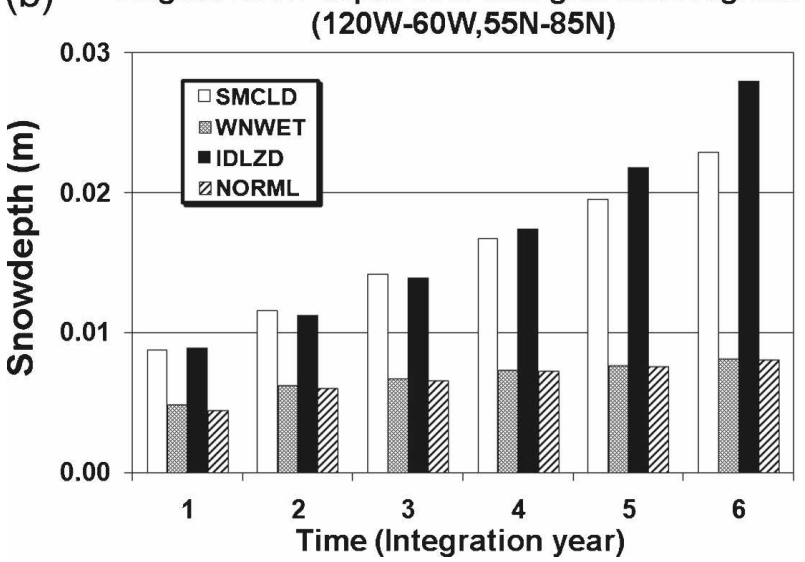

FIG. 8. Area-averaged snow depths (m) (a) for initially glaciated grids for the wet winter (WNWET) and cold summer (SMCLD) experiments and (b) in August for grids that are not glaciated initially for the four experiments.

had more than $90 \%$ of their surface still covered in snow throughout August (Fig. 6). The large fraction of ground that is still snow covered in the high elevations of Baffin and Ellesmere Islands in both experiments suggests that the presence of residual ice is important in sustaining perennial snow cover.

Figure 8 shows that, over time, the preservation of average snowfall in the preceding winter results in snow depths that are larger in the SMCLD experiment compared to the WNWET (Fig. 8a). Because the WNWET experiment had above average snowfall while the SMCLD had average snowfall, this result confirms that the summer temperatures are of primary significance for ice sheet growth. Areas that are initially glaciated (Fig. 7) occur over high terrain. Because these areas are in general colder, the development of perennial snow results in additional cooling and a tendency for snow depths to build up in both experiments, but noticeably faster in SMCLD. The differences resulting from seasonal characteristics are more distinct for the nonglaciated regions (Fig. 8b), although the depths are much smaller than those over glaciated areas. The depth of perennial snow cover over grid points that are initially nonglaciated increases more rapidly in the IDLZD and SMCLD experiments, both of which have cold summers compared to WNWET and NORML. Since cold summer temperatures act to preserve winter snowfall, the occurrence of cold spring and summers following extreme winter snowfall results in more snow being preserved in the IDLZD experiment compared to the SMCLD. The comparable depths of snow in the NORML and WNWET experiments suggest that most of the snowfall from the extremely wet winter is melted away by the average summer temperatures in both experiments. Although Fig. 8b shows small increases in snow depths in both NORML and WNWET experiments, the increases are dominated by increases in snow depth occurring in the high elevations over Baffin Island where permanent ice forms first.

\section{c. Snow area and depth}

Figure 9a shows the spatial pattern of snow depth in August of year 20 in the areas where snow cover persists throughout the summer in the simulations. It shows that greater depths of snow in the IDLZD experiment occur at higher elevations over eastern Baffin Island compared to the low areas in western Baffin. Therefore the growth of the Laurentide Ice Sheet may have started on the margins of residual ice on the slopes of Baffin Island. However, for ice sheets to grow, the areas that are initially not glaciated around Hudson Bay must develop and maintain perennial snow cover. When the atmosphere is cooled below contemporary climate extremes (Fig. 9b, BP116), areas surrounding Hudson Bay develop and maintain perennial snow cover that is greater than $5 \mathrm{~m}$ deep. The snow is deeper on the eastern side of Hudson Bay in the LabradorUngava region than in the Keewatin area on the northwestern side. The results (Fig. 9b) indicate that cold summer air temperatures lower than the coldest extreme in the ERA-40 record are required. Over southeast Baffin Island, the depths exceed $20 \mathrm{~m}$ in BP116 at the end of August over a much larger area than in the IDLZD experiment. The difference between snow depths in the east and northwest of Hudson Bay could be related to high elevations in the Torngat Mountains and the proximity to the Atlantic moisture source. A recent analysis of the free-gravity anomaly (FAGA) 

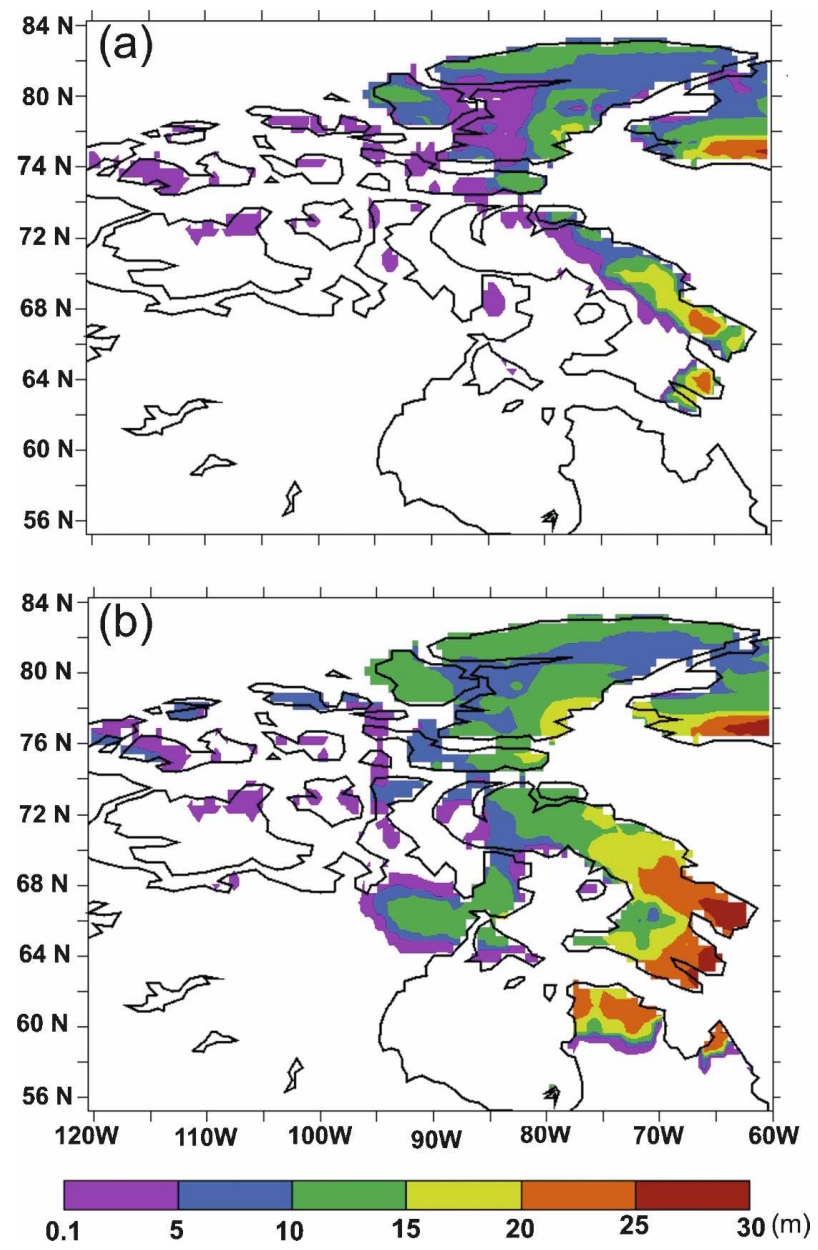

Fig. 9. Depth of snow (m) in August after 20 years of integration for the (a) IDLZD and (b) BP116 experiments.

based on the Gravity Recovery and Climate Experiment (GRACE) satellite data show that the Laurentide Ice Sheet comprised two domes (Tamisiea et al. 2007). The locations of these domes are consistent with the two areas around Hudson Bay where ice sheet growth is simulated in these experiments.

The INSOL experiment shows that, for inception from present-day conditions, insolation alone would have to reduce by at least $25 \%$. This is more than twice computed reductions in TOA insolation (Berger 1978). Even then, the resulting snow depths are relatively small $(<0.1 \mathrm{~m}$ after $5 \mathrm{yr})$ compared to more than $0.7 \mathrm{~m}$ depths at the same time in BP116 (Fig. 10). In the PDA experiment the atmospheric incident radiation, orbital configuration, and $\mathrm{CO}_{2}$ concentration in CLM3 have all been reduced to $116 \mathrm{kyr} \mathrm{BP}$ values, while the air temperature is kept at present-day values.

Figure 10 shows that snow depths over nonglaciated grid points from the PDA experiment are very close to

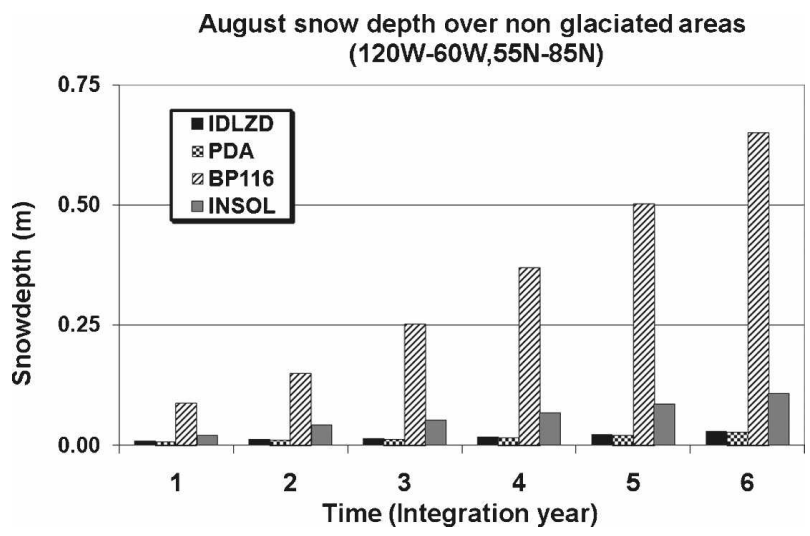

FIG. 10. Area-averaged $\left(55^{\circ}-85^{\circ} \mathrm{N}, 120^{\circ}-60^{\circ} \mathrm{W}\right)$ snow depths (m) for areas that are initially not glaciated from four experiments. (i) IDLZD: idealized atmospheric forcing comprising wet winters and cold summers and contemporary orbital configuration in CLM3; (ii) PDA: as for IDLZD but with 116-kyr orbital configuration in CLM3; (iii) BP116: as for PDA but with an additional $4^{\circ} \mathrm{C}$ cooling of the atmosphere; (iv) INSOL: as for IDLZD but with INSOL reduction (about twice the estimated reduction at the end of the Eemian) in ERA-40 incident shortwave radiation. The plot shows that snow depths from a cooler atmosphere are much larger than even those from a twofold reduction in insolation.

those in the IDLZD and neither experiment results in inception around Hudson Bay. Therefore, the PDA shows that a warm atmosphere can suppress inception even under the Eemian insolation decrease. The large reductions in insolation required for inception in INSOL experiments show that the modest reductions in insolation due to Milankovitch forcing at a time when paleorecords suggest warmer conditions (116 kyr BP) were probably insufficient for inception.

The long-term (1958-2001) area-averaged ERA-40 temperature over the inception region for summer is $\sim 280 \mathrm{~K}$ and was reduced in 1972 to $\sim 278 \mathrm{~K}$; thus the additional $4 \mathrm{~K}$ cooling would have lowered the temperature to near freezing at $274 \mathrm{~K}$. This suggests that the local reduction in surface temperature in response to Milankovitch forcing may have to be as large as $6 \mathrm{~K}$ for inception to occur. Similar reductions in temperature are suggested by paleoreconstructions at inception from ice core records from both the North Greenland Icecore Project (NorthGRIP) and Vostok, Antarctica (Landais et al. 2006).

In preliminary results (not presented) we found that an atmosphere that was colder than present-day extreme temperatures by $4^{\circ} \mathrm{C}$ resulted in inception even under present-day insolation and $\mathrm{CO}_{2}$ concentration in CLM3. How could such a large cooling have occurred at the end of the Eemian? Locally, reductions in absorbed solar radiation and the presence of perennial 


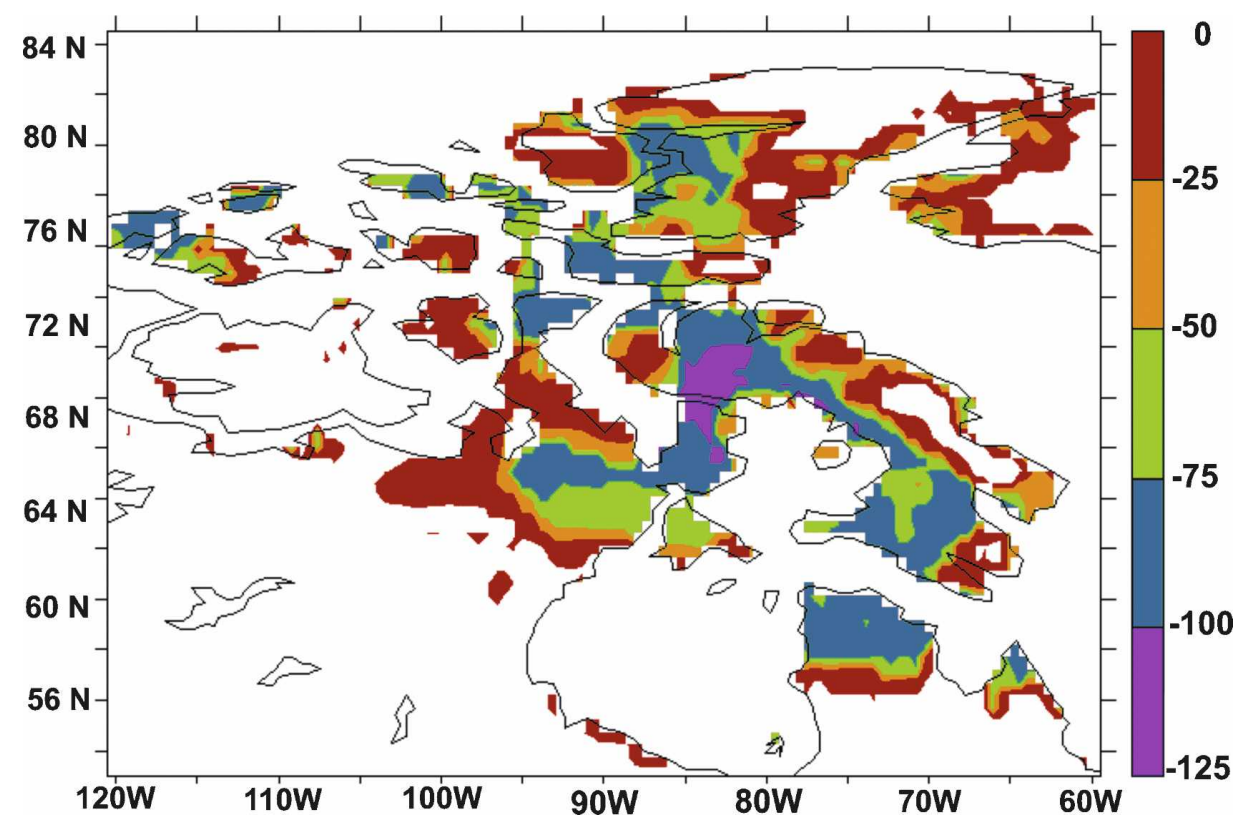

FIG. 11. Difference (BP116 minus IDLZD) in August surface solar radiation $\left(\mathrm{W} \mathrm{m}^{-2}\right)$ absorbed in year 20 of integration.

snow could lead to a cooling of the atmosphere. However the results of PDA and BP116 suggest that a cooling of the atmosphere had to occur first before perennial snow would develop. We think that this initial cooling could not have been local since much larger reductions in insolation would have been required to trigger the snow-albedo feedback. A remote source of atmospheric cooling would be consistent with the findings of Huybers and Molnar (2007) that warmer eastern equatorial Pacific Ocean SST before $3 \mathrm{Myr}$ precluded glaciation and that cooling of the eastern equatorial Pacific after this period resulted in favorable conditions for inception. Khodri et al. (2005) suggest that a cooling of the high latitudes resulted in increased snowfall. Thus a cooler atmosphere would provide favorable conditions by allowing for increased snowfall and surface cooling required for inception. The IDLZD experiment showed that increased snowfall and colder temperatures do not provide ideal conditions for ice sheet growth. Therefore, an initial widespread cooling was necessary to trigger feedbacks that led to growth of the Laurentide Ice Sheet.

\section{d. Role of snow-albedo feedbacks}

The ratio (not shown) of absorbed to incident shortwave radiation shows that the greatest absorption at the surface occurs in June-August. Over western Baffin and Ellesmere Islands, the absorption reaches maximum in August. In the high elevations of both islands the fraction absorbed even in August remains below $40 \%$ and these areas are permanently covered by glacial ice. The glacial ice influences the fraction of the ground that is snow covered during April-September and, hence, the surface albedo. Higher reflectivity limits the summer temperatures and hence summer snowmelt. In Fig. 6 we saw that most of the grid points in Baffin and Ellesmere Islands are still covered by snow at the end of August in the BP116 simulation. The significance of this perennial snow cover is evident in the reduction of the solar radiation that is absorbed. Figure 11 shows reductions in absorbed shortwave radiation around Keewatin and Labrador-Ungava that exceed 75 $\mathrm{W} \mathrm{m}{ }^{-2}$ in the BP116 experiment compared to the IDLZD. Decreases in absorbed solar radiation of more than $100 \mathrm{~W} \mathrm{~m}^{-2}$ occur over northern Baffin Island. Deep perennial snow in these areas reflects more shortwave radiation leading to the decrease in absorbed fraction. This decrease results in lower temperature, which enhances the build up of perennial snow.

By decreasing the amount of absorbed solar radiation, the high albedo of perennial snow cover decreases the heat flux into the soil, triggering a positive feedback in which more snow builds up and further increases the amount of reflected shortwave radiation. The decrease in heat flux into the soil also decreases the soil temperature. Snow falling on this colder surface is therefore likely to remain on the ground instead of melting away. Figure 12 shows changes in soil temperature with 
(a) Soil temperatures for IDLZD

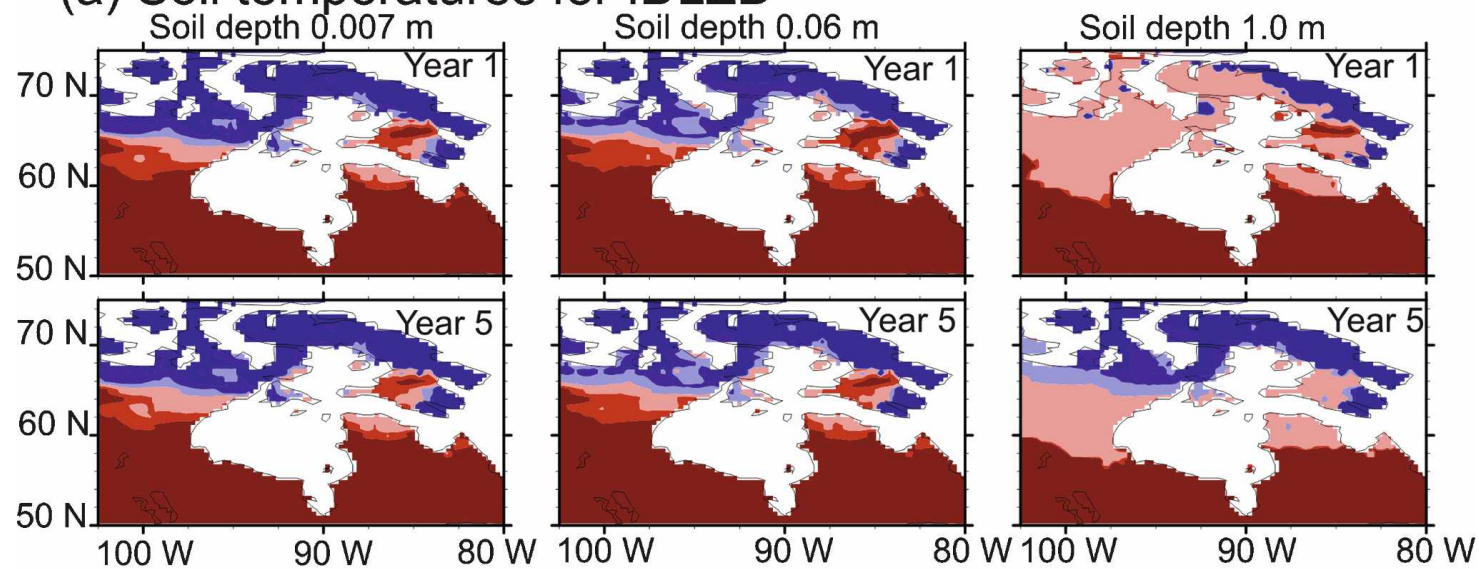

(b) Soil temperatures for BP116

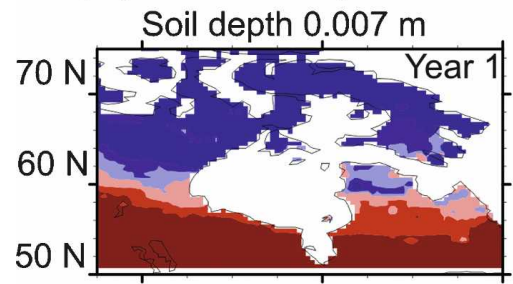

Soil depth $0.06 \mathrm{~m}$
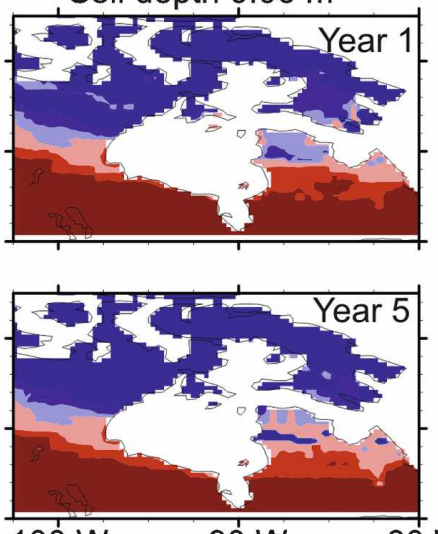

80
Soil depth $1.0 \mathrm{~m}$
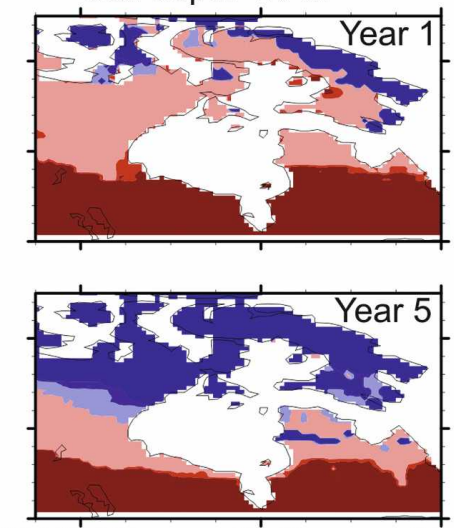

$90 \mathrm{~W} \quad 80 \mathrm{~W}$

\section{$\begin{array}{lllllll}271.5 & 272.0 & 272.5 & 273.0 & 273.5 & 274.0 & 274.5\end{array}$}

FIG. 12. Soil temperatures at 3 depths (columns) at year 1 (first row) and year 5 (second row) for the (a) IDLZD experiment and (b) BP116 experiment. Soil temperatures are below freezing from the surface down to $1 \mathrm{~m}$ after $5 \mathrm{yr}$ in the areas showing deep perennial snow. Areas with temperatures greater than $274 \mathrm{~K}$ do not develop perennial snow in both experiments.

depth (columns) and time (rows). The soil temperatures changes very slowly after year 5 and within the layers below the surface. Therefore the spatial patterns (Fig. 12) are given for years 1 and 5 and for depths at 0.007 (near surface), 0.06 , and $1.0 \mathrm{~m}$. Figure 12a shows the soil temperatures for the IDLZD experiment, while the BP116 is shown in Fig. 12b. It is evident that soil temperatures drop below freezing down to $1 \mathrm{~m}$ by year 5 in both experiments north of $65^{\circ} \mathrm{N}$, but the area of below freezing temperatures is larger in the BP116, consistent with the southward expansion of perennial snow. Areas where the temperature remains above 274 $\mathrm{K}$ never develop perennial snow even after 20 years of integration.

\section{Summary and discussion}

This study examined whether or not perennial snow cover required for ice sheet growth can develop in response to increases in frequency of extremely wet winters and cold summer seasons due to changes in atmospheric circulations in the region associated with the inception of the Laurentide Ice Sheet for the presentday and the Eemian. Incident shortwave radiation and air temperatures in ERA-40 were adjusted to minimize known biases and to account for changes in insolation and temperature toward the end of the Eemian before being used to drive CLM3. The idealized year comprised a wet winter followed by cold spring and summer 


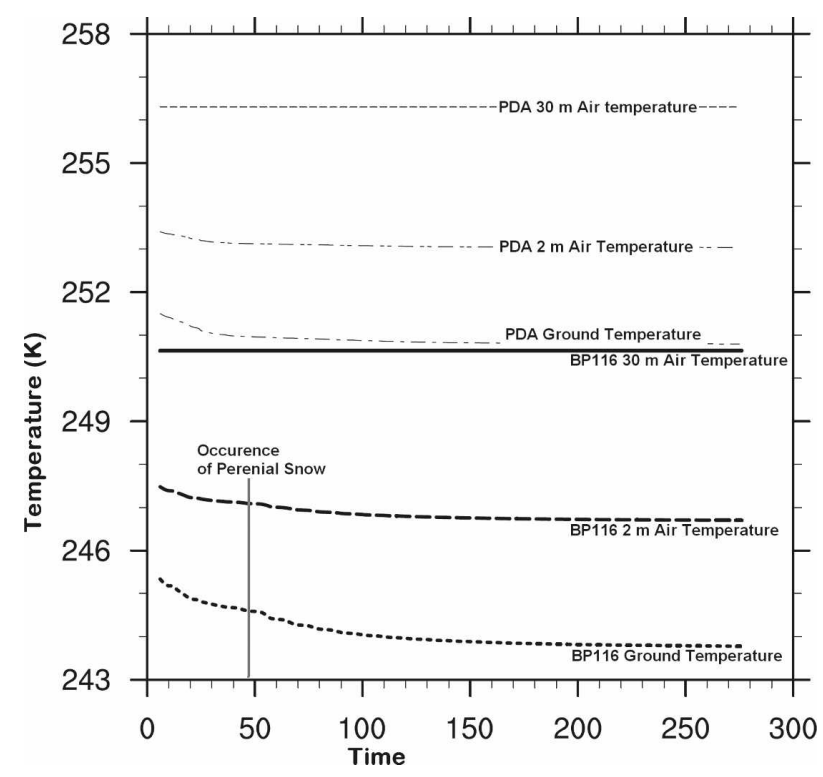

FIG. 13. Twelve-month running mean of area-averaged temperatures in the atmospheric forcing $(30 \mathrm{~m})$ and the CLM3computed air $(2 \mathrm{~m})$ and ground temperature for the PDA (thin lines) and BP116 (thick line) experiments. The vertical line on the lower left marks the approximate time of first occurrence of perennial snow (inception).

seasons defined from present-day extremes. The changes in insolation at the top of the atmosphere based on the earth's position in its orbit were used at the surface in this study.

Incident solar radiation is usually absorbed by the earth's surface, water vapor, and other gases in the atmosphere. About half of the incident insolation warms the earth through local absorption by land and ocean; we will refer to this as local forcing henceforth. Local air temperatures can also change due to horizontal advection of warm or cold air. The airmass gains or looses heat elsewhere as it approaches the inception region, and we consider this a remote forcing. Feedback processes involving sea ice and/or Pacific SSTs can also remotely influence local temperature. Although greenhouse gases are uniformly distributed globally, the effects could be large locally. These effects have been included indirectly in the atmospheric forcing through temperature adjustments and directly in CLM3 by specifying the $\mathrm{CO}_{2}$ concentration.

The results demonstrate that insolation reduction alone would have to be very large to provide sufficient local cooling for inception. This raises the question of whether the local reduction in insolation at $116 \mathrm{kyr}$ BP would have been sufficient for inception. While we cannot demonstrate that increased horizontal cold air advection led to inception of the Laurentide Ice Sheet, the results demonstrate that a colder atmosphere had a de- cisive role in the inception. How this cooling would have been achieved requires additional studies.

We find that CLM3 is able to simulate important processes that influence the onset and growth of ice sheets. Larger changes in insolation or temperature that cannot be accounted for by orbital variations alone are required to initiate perennial snow in the contemporary and 116-kyr-BP climate, respectively. Colder summer temperatures are found to be more important than extreme winter snowfall for inception. Extreme winter snowfall is almost completely melted away by normal summer temperatures. The results show that increases in the frequency of wet winters and cold springs and summers are not sufficient for development of perennial snow in the low-lying areas around Hudson Bay and hence inception under both contemporary and Eemian conditions. Only in the high elevations of Baffin Island and in areas that are glaciated is perennial snow enhanced as a result of frequency increases. Thus, the growth of the Laurentide Ice Sheet may have started at these high elevations. This is consistent with previous results that suggest the ice sheet growth occurred through a lowering of the snow line. Barry et al. (1975) discuss field evidence in support of snow line lowering based on lichen-free surfaces on upland surfaces of Baffin Island. The Torngat Mountains on the Labrador Peninsula and the proximity to the moisture source from the North Atlantic Ocean appear to contribute to the much deeper snow cover in the Labrador-Ungava area east of Hudson Bay compared to the Keewatin area when additional summer cooling is imposed. Ives (1957) concluded that the highest peaks of the Torngat Mountains were completely submerged in ice and that the most likely method of initiation of the continental ice sheet in this area was instantaneous glaciation of the Labrador-Ungava Plateau. The location of the domes based on analysis of a free-gravity anomaly is consistent with the locations where the CLM3 has deepest snow at this early stage in the inception, suggesting that the Laurentide Ice Sheet grew over land. As the ice sheet grew and sea level dropped, more land would have been exposed over the region, allowing for a southward expansion of the ice sheet.

The experimental setup in this study allowed us to constrain the atmosphere in perpetual idealized winter or summer cycles. To some extent this approach may limit the influence of the perennial snow cover on the atmosphere above. We attempted to assess the impact of constraining the 30-m temperatures to fixed presentday seasonal values by looking at the ground and surface air $(2 \mathrm{~m})$ temperatures computed by CLM3 (Fig. 13). We think that these have a stronger influence on 
the development of perennial snow compared to the 30-m air temperature. As expected the annual average (12-month running mean) forcing temperature at $30 \mathrm{~m}$ remains constant throughout the integration. However, the surface air and ground temperatures decrease in response to the extremely cold atmosphere above. We note that additional cooling occurs in the BP116 after the development of perennial snow. The PDA experiment, on the other hand, appears to reach equilibrium after about 40 months without any significant cooling trend thereafter. The snow-albedo feedback present in BP116 results in decreased ground temperatures in BP116 that is about twice $(1.7 \mathrm{~K})$ that of the PDA $(\sim 0.7 \mathrm{~K})$. The ground and air temperatures show rapid cooling $\left(>0.5 \mathrm{~K} \mathrm{yr}^{-1}\right)$, which levels off after the first $6 \mathrm{yr}$ (60 months). Therefore, persistent extremes lasting several decades may not be necessary once snow-albedo feedbacks are triggered. It is possible that additional cooling could occur if the 30-m air temperature was free to respond to the presence of perennial snow. However, one would have to assume that other changes in the atmosphere such as cloud cover and horizontal advection would be favorable. The response of the coupled system is likely more complex than this and is the subject of a future paper. We thus consider the experimental configuration used here as adequate because it captures the main feedback (snow-albedo cooling of ground and surface air) and does not unduly constrain the land-atmosphere interface where perennial snow and growth of ice sheet occurs.

\section{Conclusions}

We conclude that increases in frequency of extremely wet winter and cold spring and summer seasons are not sufficient for inception under both present-day and 116kyr-BP insolation. Growth of ice sheets into areas that are initially not glaciated is difficult and requires at least an additional $4^{\circ} \mathrm{C}$ of summer cooling. Decreases in annual air temperatures that are up to $6^{\circ} \mathrm{C}$ in both hemispheres have been inferred from ice core records at the end of the Eemian. We therefore conclude that the mechanism for inception of the Laurentide Ice Sheet required widespread spread cooling of the atmosphere. Owing to the large reduction in insolation required for inception, we think that such widespread cooling would have required a source outside the inception area. Thus, by developing perennial snow in response to the cooler atmosphere, the inception region does not initiate glaciers but responds by forming them. A remotely forced warming sufficient to maintain present-day temperatures in the onset region precludes inception even with favorable 116-kyr-BP conditions. The mechanism for the widespread cooling of the at- mosphere suggested here is not clear and requires additional research into teleconnections to the tropics, $\mathrm{CO}_{2}$ sequestration, and perturbations in atmospheric dynamics, as suggested by recent studies (Huybers and Molnar 2007; Skinner 2006; Hall et al. 2005).

We acknowledge that, as a column model, CLM3 is not capable of simulating lateral spreading of snow that would result from the cooling effect of drainage winds and the downslope advection of accumulated snow above a grid point. Because CLM3 is a land model it does not simulate sea ice, which would develop in the water surrounding the islands. The presence of sea ice would contribute to additional cooling through reflection of shortwave radiation. The results also indicate the need for a fully interactive atmospheric coupling to further understand the interaction of the perennial snow with the atmosphere above. In addition, atmospheric patterns in the contemporary climate do not show persistent extremes on decadal scales as used in the experiments here. However, the tendency for inception after only five years of colder extremes suggests that such persistence on multidecadal time scales may not be necessary. Since the completion of these experiments a new version of the land model (CLM3.5) has been released with changes that lower the snow albedo by accounting for the effect of snow aging. These changes are likely to reduce the rate at which the snow depth increases in our simulations but would not change our main results.

Acknowledgments. This research was funded by NSF Grant OPP-0352865. ERA-40 data were obtained from the University Corporation for Atmospheric Research data support section (http://www.dss.ucar.edu). The computations were done at NCAR using resources provided by the Scientific Computing Division (SCD36091015). The authors are grateful to Samuel Levis for help with setting up CLM3 to efficiently execute on bluevista at NCAR and to David Stepaniak and ShengHung Wang for assistance with interpolation of ERA40 data. This work benefited immensely from preliminary analysis performed by the late Richard Toracinta. We thank Robert Oglesby for his comments that helped us improve the manuscript. We are also grateful to Michel Crucifix and Yosef Ashkenazy for helpful discussions on insolation differences between $116 \mathrm{kyr}$ $\mathrm{BP}$ and present-day. We appreciate the comments of the three anonymous reviewers that have also helped improve the quality of the manuscript substantially.

\section{REFERENCES}

Adam, J. C., E. A. Clark, D. P. Lettenmaier, and E. F. Woods, 2006: Correction of global precipitation products for orographic effects. J. Climate, 19, 15-38. 
Adler, R. F., and Coauthors, 2003: The version-2 Global Precipitation Climatology Project (GPCP) monthly precipitation analysis (1979-present). J. Hydrometeor., 4, 1147-1167.

Alt, B. T., 1987: Developing synoptic analogs for extreme mass balance conditions on Queen Elizabeth Island ice caps. $J$. Climate Appl. Meteor., 26, 1605-1623.

Anderson, E. A., 1976: A point energy and mass balance model of a snow cover. NOAA Tech. Rep. NWS 19, Office of Hydrology, National Weather Service, Silver Spring, MD, 150 pp.

Andrews, J. T., and R. G. Barry, 1978: Glacial inception and disintegration during the last glaciation. Annu. Rev. Earth Planet. Sci., 6, 205-228.

Barry, R. G., 1966: Meteorological aspects of the glacial history of Labrador-Ungava with special reference to atmospheric vapour transport. Geogr. Bull., 8, 319-340.

_ J. T. Andrews, and M. A. Mahaffy, 1975: Continental ice sheets: Conditions for growth. Science, 190, 979-981.

Berg, A., and J. S. Famiglietti, 2003: Impact of bias correction to reanalysis products on simulations of North American soil moisture and hydrological fluxes. J. Geophys. Res., 108, 4490, doi:10.1029/2002JD003334.

Berger, A., 1978: Long term variations of daily insolation and quaternary climatic changes. J. Atmos. Sci., 35, 2362-2367.

Bianca, F., A. P. Wolfe, G. H. Miller, H. Gifford, R. J. H. Pierre, and A. de Vernal, 2006: Vegetation and climate of the last interglacial on Baffin Island, Arctic Canada. Palaeogeogr. Palaeoclimatol. Palaeoecol., 236, 91-106.

Bonan, G. B., 1996: A land surface model (LSM version 1.0) for ecological, hydrological, and atmospheric studies: Technical description and user's guide. NCAR Tech. Note NCAR/TN$417+$ STR, $150 \mathrm{pp}$.

— , and S. Levis, 2006: Evaluating aspects of the Community Land and Atmosphere Models (CLM3 and CAM3) using a dynamic global vegetation model. J. Climate, 19, 2302-2324.

—, K. W. Oleson, M. Vertenstein, S. Levis, X. Zeng, Y. Dai, R. E. Dickinson, and Z. Yang, 2002: The land surface climatology of the Community Land Model coupled to the NCAR Community Climate Model. J. Climate, 15, 3123-3149.

Box, J., J. Key, J. Maslanik, and M. C. Serreze, 1998: Arctic Global Radiation (AGR) data set. National Snow and Ice Data Center, Boulder, CO, digital media. [Available online at http://nsidc.org/data/arcss066.html.]

Broecker, W. S., and J. van Donk, 1970: Insolation changes, ice volume, and the $\mathrm{O} 18$ record in deep-sea cores. Rev. Geophys. Space Phys., 8, 169-198.

- D. L. Thurber, J. Goddard, T. Ku, R. K. Matthews, and K. J. Mesolella, 1968: Milankovitch hypothesis supported by precise dating of coral reef and deep-sea sediments. Science, $\mathbf{1 5 9}$, 297-300.

Bromwich, D. H., and S.-H. Wang, 2005: Evaluation of the NCEP/ NCAR and ECMWF 15/40-yr reanalyses using rawinsonde data from two independent Arctic field experiments. Mon. Wea. Rev., 133, 3562-3578.

_, E. R. Toracinta, and S.-H. Wang, 2002: Meteorological perspective on the initiation of the Laurentide Ice Sheet. Quat. Int., 95-96, 113-124.

—, R. L. Fogt, K. E. Hodges, and J. E. Walsh, 2007: A tropospheric assessment of the ERA-40, NCEP, and JRA-25 global reanalyses in the polar regions. J. Geophys. Res., 112, D10111, doi:10.1029/2006JD007859.

Chen, M., P. Xie, J. E. Janowiak, and P. Arkin, 2002: Global land precipitation: A 50-yr monthly analysis based on gauge observations. J. Hydrometeor., 3, 249-266.
Collins, W. D., and Coauthors, 2006: The Community Climate System Model version 3 (CCSM3). J. Climate, 19, 2122-2143.

Crucifix, M., M. F. Loutre, and A. Berger, 2006: The climate response to astronomical forcing. Space Sci. Rev., 125, 213-226.

Cullather, R. I., D. H. Bromwich, and M. C. Serreze, 2000: The atmospheric hydrologic cycle over the Arctic basin from reanalyses. Part I: Comparison with observations and previous studies. J. Climate, 13, 923-937.

Dai, Y., and Q.-C. Zeng, 1997: A land surface model (IAP94) for climate studies, Part I: Formulation and validation in off-line experiments. Adv. Atmos. Sci., 14, 433-460.

De Noblet, N. I., I. C. Prentice, S. Joussaume, D. Texier, A. Botta, and A. Haxeltine, 1996: Possible role of atmospherebiosphere interactions in triggering the last glaciation. Geophys. Res. Lett., 23, 3191-3194.

Dickinson, R. E., A. Henderson-Sellers, P. J. Kennedy, and M. F. Wilson, 1993: Biosphere-Atmosphere Transfer Scheme (BATS) version 1e coupled to Community Climate Model. NCAR Tech. Note NCAR/TN-387+STR, 72 pp.

- , K. W. Oleson, G. Bonan, F. Hoffman, P. Thornton, M. Vertenstein, Z.-L. Yang, and X. Zeng, 2006: The Community Land Model and its climate statistics as a component of the Community Climate System Model. J. Climate, 19, 23252346.

Dong, B., and P. J. Valdes, 1995: Sensitivity studies of Northern Hemisphere glaciation using an atmospheric general circulation model. J. Climate, 8, 2471-2496.

Gardner, A. S., and M. Sharp, 2007: Influence of the Arctic circumpolar vortex on the mass balance of Canadian high Arctic glaciers. J. Climate, 20, 4586-4598.

Gebhardt, C., N. Kühl, A. Hensel, and T. Litt, 2007: Reconstruction of quaternary temperature fields by dynamically consistent smoothing. Climate Dyn., 30, 421-437, doi:10.1007/ s00382-007-0299-9.

Gibson, J. K., P. Kallberg, A. Hernandez, S. Upalla, A. Nomura, and S. Serrano, 1997: ERA description. Vol. 1, European Centre for Medium-Range Weather Forecasts, 72 pp.

Goodison, B. E., P. Y. T. Louie, and D. Yang, 1998: WMO solid precipitation measurement intercomparison. World Meteorological Organization Tech. Doc. WMO/TD 872, 212 pp.

Hall, A., A. Clement, D. W. J. Thompson, A. Broccoli, and C. Jackson, 2005: The importance of atmospheric dynamics in the Northern Hemisphere winter climate response to changes in the earth's orbit. J. Climate, 18, 1315-1325.

Hays, J. D., J. Imbrie, and N. J. Shackleton, 1976: Variations in the earth's orbit: Pacemaker of the Ice Ages. Science, 194, $1121-1132$.

Huybers, P., and P. Molnar, 2007: Tropical cooling and the onset of North American glaciation. Climate Past Discuss., 3, 771789.

Ives, J. D., 1957: Glaciation of the Torngat Mountains, northern Labrador. Arctic, 10, 67-87.

Jacobs, J. D., R. G. Barry, R. S. Bradley, and R. L. Weaver, 1974: Studies of climate and ice conditions in eastern Baffin Island, 1971-1973. Occasional Paper 9, University of Colorado, Institute of Arctic and Alpine Research, Boulder, CO, 78 pp.

Jordan, R., 1991: A one-dimensional temperature model for a snow cover: Technical documentation for SNTHERM.89. U.S. Army Cold Regions Research and Engineering Laboratory, Special Rep. 91-16, 49 pp.

Joussaume, S., and P. Braconnot, 1997: Sensitivity of paleoclimate simulation results to season definitions. J. Geophys. Res., 102, 1943-1956. 
Kalnay, E., and Coauthors, 1996: The NCEP/NCAR 40-Year Reanalysis Project. Bull. Amer. Meteor. Soc., 77, 437-471.

Khodri, M., Y. Leclainche, G. Ramstein, P. Braconnot, O. Marti, and E. Cortijo, 2001: Simulating the amplification of orbital forcing by ocean feedbacks in the last glaciation. Nature, 410, 570-574, doi:10.1038/35069044.

—, M. A. Cane, G. Kukla, J. Gavin, and P. Braconnot, 2005: The impact of precession changes on the Arctic climate during the last interglacial-glacial transition. Earth Planet. Sci. Lett., 236, 285-304.

Kubatzki, C., M. Claussen, R. Calov, and A. Ganopolski, 2006: Sensitivity of the last glacial inception to initial and surface conditions. Climate Dyn., 27, 333-344.

Kühl, N., and T. Litt, 2003: Quantitative time series reconstruction of Eemian temperature at three European sites using pollen data. Veg. Hist. Archaeobot., 12, 205-214.

Kukla, G. J., and A. Kocí, 1972: End of the last interglacial in the loess record. Quat. Res., 2, 374-383.

Kutzbach, J. E., and B. L. Otto-Bliesner, 1982: The sensitivity of the African-Asian monsoon climate orbital parameter changes for 900 years B.P. in a low-resolution general circulation model. J. Atmos. Sci., 39, 1177-1188.

Landais, A., and Coauthors, 2006: The glacial inception as recorded in the NorthGRIP Greenland ice core: Timing, structure and associated abrupt temperature changes. Climate Dyn., 26, 273-284.

Laskar, J., F. Joutel, and F. Boudin, 1993: Orbital precessional and insolation quantities for the earth from $-20 \mathrm{Myr}$ to $+10 \mathrm{Myr}$. Astron. Astrophys., 270, 522-533.

Levis, S., G. B. Bonan, M. Vertenstein, and K. W. Oleson, 2004: The Community Land Model's Dynamic Global Vegetation Model (CLM-DGVM): Technical description and user's guide. NCAR Tech. Note NCAR/TN-459+IA, 50 pp.

Loewe, F., 1971: Considerations on the origin of the quaternary ice sheet of North America. Arct. Alp. Res., 3, 331-344.

Matsuura, K., and C. J. Willmott, 2005: Arctic land-surface precipitation: 1930-2004 gridded monthly time series (version 1.03). Digital media. [Available online at http://climate.geog. udel.edu/ climate/html_pages/download.html\#ac_precip_ ts4.]

Meisner, K. J., A. J. Weaver, H. D. Matthews, and P. M. Cox, 2003: The role of land surface dynamics in glacial inception: A study with the UVic Earth System Model. Climate Dyn., 21, 515-537.

Milankovitch, M., 1941: Canon of Insolation and the Ice Age Problem. Translation 1969, Jerusalem, Israel Program for Scientific Translations, 484 pp. [Available from U.S. Dept. of Commerce, Clearinghouse for Federal Scientific and Technical Information, Springfield, VA 22161.]

Muller, R. A., and G. J. MacDonald, 1997: Glacial cycles and astronomical forcing. Science, 277, 215-218.

Oleson, K., and Coauthors, 2004: Technical description of the Community Land Model (CLM). NCAR Tech. Note NCAR/ TN-461+STR, 164 pp.

Qian, T., A. Dai, K. Trenberth, and K. W. Oleson, 2006: Simulations of global land surface conditions from 1948 to 2004. Part I: Forcing data and evaluations. J. Hydrometeor., 7, 953-975.

Ramstein, G., M. Khodri, Y. Donnadieu, F. Fluteau, and Y. Goddéris, 2005: Impact of the hydrological cycle on past climate changes: Three illustrations at different time scales. $C . R$. Geosci., 337, 125-137.

Reichert, B. K., L. M. Bengtsson, and J. Oerlemans, 2001: Mid- latitude forcing for glacier mass balance investigated using general circulation models. J. Climate, 14, 3767-3784.

Rind, D., D. Peteet, and G. Kukla, 1989: Can Milankovitch orbital variations initiate the growth of ice sheets in a general circulation model? J. Geophys. Res., 94, 12 851-12 871.

Rogers, A. N., D. H. Bromwich, E. N. Sinclair, and R. I. Cullather, 2001: The atmospheric hydrologic cycle over the Arctic basin from reanalyses. Part II: Interannual variability. $J$. Climate, 14, 2414-2429.

Ruddiman, W. F., 2006: Orbital changes and climate. Quat. Sci. Rev., 25, 3092-3112.

Serreze, M. C., and J. A. Maslanik, 1997: Arctic precipitation as represented in the NCEP/NCAR reanalysis. Ann. Glaciol., 25, 429-433.

, and C. M. Hurst, 2000: Representation of mean Arctic precipitation from NCEP-NCAR and ERA reanalyses. J. Climate, 13, 182-201.

, J. R. Key, J. E. Box, J. A. Maslanik, and K. Steffen, 1998: A new monthly climatology of global radiation for the Arctic and comparisons with NCEP-NCAR reanalysis and ISCCPC2 fields. J. Climate, 11, 121-136.

—, M. P. Clark, and D. H. Bromwich, 2003: Monitoring precipitation over the Arctic terrestrial drainage system: Data requirements, shortcomings, and applications of atmospheric reanalysis. J. Hydrometeor., 4, 387-407.

— A. P. Barrett, and F. Lo, 2005: Northern high-latitude precipitation as depicted by atmospheric reanalyses and satellite retrievals. Mon. Wea. Rev., 133, 3407-3430.

Sheffield, J., A. D. Ziegler, E. F. Wood, and Y. Chen, 2004: Correction of the high-latitude rain day anomaly in the NCEPNCAR reanalysis for land surface hydrological modeling. $J$. Climate, 17, 3814-3828.

Skinner, L. C., 2006: Glacial-interglacial atmospheric $\mathrm{CO}_{2}$ change: A simple hypsometric effect on deep-ocean carbon sequestration. Climate Past Discuss, 2, 711-743.

Sloss, P. W., 2001: ETOPO2: 2 minute worldwide bathymetry/ topography data. National Geophysical Data Center (NGDC) ETOPO2 global 2' elevations, CD-ROM. [Available from NOAA/NGDC Mail Code E/GC3, 325 Broadway, Boulder, CO 80305.]

Soon, W., 2007: Implications of the secondary role of carbon dioxide and methane forcing in climate change: Past, present, and future. Phys. Geogr., 28, 193-275.

Stott, L., A. Timmermann, and R. Thunell, 2007: Southern Hemisphere and deep-sea warming led deglacial atmospheric $\mathrm{CO}_{2}$ rise and tropical warming. Science, 318, 435-438.

Tamisiea, M. E., J. X. Mitrovica, and J. L. Davis, 2007: GRACE gravity data constrain ancient ice geometries and continental dynamics over Laurentia. Science, 316, 881-883.

Tian, X., A. Dai, D. Yang, and Z. Xie, 2007: Effects of precipitation-bias corrections on the surface hydrology over northern latitudes. J. Geophys. Res., 112, D14101, doi:10.1029/ 2007JD008420.

Uppala, S. M., and Coauthors, 2005: The ERA-40 Re-Analysis. Quart. J. Roy. Meteor. Soc., 131, 2961-3012, doi:10.1256/ qj.04.176.

Vertenstein, M., F. Hoffman, K. Oleson, and S. Levis, 2004: Community Land Model Version 3.0 (CLM3.0) user's guide. 39 pp. [Available online at http://www.cgd.ucar.edu/tss/clm/ distribution/clm3.0/UsersGuide/UsersGuide.pdf.]

Vettoretti, G., and W. R. Peltier, 2003: Post-Eemian glacial inception. Part II: Elements of a cryospheric moisture pump. $J$. Climate, 16, 912-927. 
_ and - 2004: Sensitivity of glacial inception to orbital and greenhouse gas climate forcing. Quat. Sci. Rev., 23, 499-519.

Willet, H. C., and F. Sanders, 1959: Descriptive Meteorology. 2nd ed. Academic Press, 355 pp.

Williams, L. D., 1979: An energy balance model of potential glacierization of Northern Canada. Arct. Alp. Res., 11, 443-456.

Willmott, C. J., and M. A. Rawlins, 1999: Arctic land-surface air temperature: Gridded monthly and annual climatologies (version 1.01). [Available online at http://climate.geog. udel.edu/ climate/html_pages/ac_readme/README.temp. clim.html.]

Yang, D., D. Kane, and Z. Zhang, 2005: Bias correction of longterm (1973-2004) daily precipitation data over northern regions. Geophys. Res. Lett., 32, L19501, doi:10.1029/ 2005 G1024057.

Yoshimori, M., M. C. Reader, A. J. Weaver, and N. A. McFar- lane, 2002: On the causes of glacial inception at $116 \mathrm{ka}$ BP Climate Dyn., 18, 383-402.

Zeng, X., M. Shaikh, Y. Dai, R. E. Dickinson, and R. Mynenic, 2002: Coupling of the Common Land Model to the NCAR Community Climate Model. J. Climate, 15, 1832-1854.

Zhang, T., K. Stamnes, and S. A. Bowling, 1996: Impact of clouds on surface radiative fluxes and snowmelt in the Arctic and subarctic. J. Climate, 9, 2110-2123.

S. A. Bowling, and K. Stamnes, 1997: Impact of the atmosphere on surface radiative fluxes and snowmelt in the Arctic and subarctic. J. Geophys. Res., 102, 4287-4302.

K. Stamnes, and S. A. Bowling, 2001: Impact of the atmospheric thickness on the atmospheric downwelling longwave radiation and snowmelt under clear-sky conditions in the Arctic and subarctic. J. Climate, 14, 920-939. 